\title{
REVIEW
}

\section{A Review of Experimental and Off-Label Therapies for Clostridium difficile Infection}

\author{
Csaba Fehér (1D · Alex Soriano · Josep Mensa
}

Received: October 26, 2016 / Published online: December 1, 2016

(C) The Author(s) 2016. This article is published with open access at Springerlink.com

\begin{abstract}
In spite of increased awareness and the efforts taken to optimize Clostridium difficile infection (CDI) management, with the limited number of currently available antibiotics for $C$. difficile the halt of this increasing epidemic remains out of reach. There are, however, close to 80 alternative treatment methods with controversial anti-clostridial efficacy or in experimental phase today. Indeed, some of these therapies are expected to become

of CDI management, which are primary prophylaxis in the susceptible population, clinical cure of severe cases, prevention of recurrences, and forestallment of asymptomatic $C$. difficile carriage and in-hospital spread. Yet, the greater the variety of treatment choices on hand, the better combination strategies can be developed to reach these goals in the future. The aim of this article is to provide a comprehensive summary of these experimental and currently off-label therapeutic options.
\end{abstract} acknowledged members of the recommended anti-CDI arsenal within the next few years. None of these alternative treatment methods can respond in itself to all the major challenges

Enhanced content To view enhanced content for this article go to http://www.medengine.com/Redeem/ B627F0601816F2B0.

C. Fehér $(\bowtie) \cdot$ A. Soriano $\cdot$ J. Mensa

Department of Infectious Diseases, Hospital Clínic of Barcelona, Barcelona, Spain

e-mail: cfeher@clinic.ub.es

A. Soriano $\cdot$ J. Mensa

August Pi i Sunyer Biomedical Research Institute (IDIBAPS), Barcelona, Spain

A. Soriano

University of Barcelona, Barcelona, Spain
Keywords: Clinical development pipeline; Clostridium difficile infection (CDI); Controversial therapies; Experimental therapies

\section{INTRODUCTION}

Clostridium difficile infection (CDI) has been increasingly recognized in recent years as an entity of primary importance that requires prompt diagnosis and efficient treatment to prevent a severe and complicated disease course, in-hospital spread and recurrences. However, due to the spore-forming ability of 
C. difficile, the impaired host intestinal microbiota and the altered immunity of CDI patients, current treatment strategies often have suboptimal results with regard to clinical cure and relapse prevention alike. In fact, present therapeutic options leave ample room for improvement in terms of clinical outcome, as the average cure rates achieved by the three main antibiotics currently recommended for CDI treatment (metronidazole, vancomycin and fidaxomicin $[1,2]$ ) do not exceed $80-90 \%$ [3]. Although fidaxomicin boasts significantly lower relapse rates than the other two alternatives, sustained cure (that is cure without recurrence) may be as low as 75\% among patients treated with this best available option $[4,5]$.

The urgent need for more efficient tools to fight CDI makes it unsurprising that today there are an impressive number of novel antibiotics and other therapies at different stages of development, some of them already being tested in phase III randomized controlled trials (RCTs). At the same time, some long-known drugs that are currently not recommended for CDI have been revisited lately to check whether there is potential room for them in the arsenal of anti-CDI therapeutics. The aim of this review is to summarize novel, neglected and controversial CDI treatment options, some of which may become part of everyday practice in the near future.

There are various criteria according to which one may classify these therapies (mode of administration, predominantly prophylactic vs. therapeutic agents, natural vs. synthetic products, etc.). In this article we resume them according to the major therapeutic effect that is sought by their application (Fig. 1). Accordingly, the majority of these products can fit in one of the following categories: (1) antibiotics and non-antibiotic agents with bacteriostatic/bactericidal effect against $C$. difficile; (2) toxin-neutralizing agents; (3) therapies that boost host immune defense against CDI; (4) treatments that modulate the intestinal environment to make it less favorable for C. difficile colonization; anti-inflammatory substances that prevent or reduce enterocyte damage caused by $C$. difficile toxins. Table 1 summarizes all therapies discussed in the following, along with their current phase of development.

\section{Compliance with Ethics Guidelines}

This article is based on previously conducted studies and does not involve any new studies of human or animal subjects performed by any of the authors.

\section{ANTIBIOTICS AND NON-ANTIBIOTIC ANTICLOSTRIDIAL AGENTS}

Similarly to the three main currently recommended anti-clostridial drugs, the majority of off-label and experimental therapeutic options seek to have a direct effect on the causative microorganism. These antibiotics and non-antibiotic agents target certain molecular components of $C$. difficile with the aim of eliminating the bacteria in an already established infection. They are presented in the following, grouped according to their main mechanism of action.

\section{Inhibitors of Transcription and DNA Synthesis}

\section{Rifamycins}

Rifaximin is a semisynthetic, nonabsorbable derivative of rifamycin that inhibits bacterial 
antibiotics

C. difficile spores vegetative $C$. difficile C. difficile toxins $\square$ enterocytes

Q. normal gut microbiota lymphocytes

neutrophils

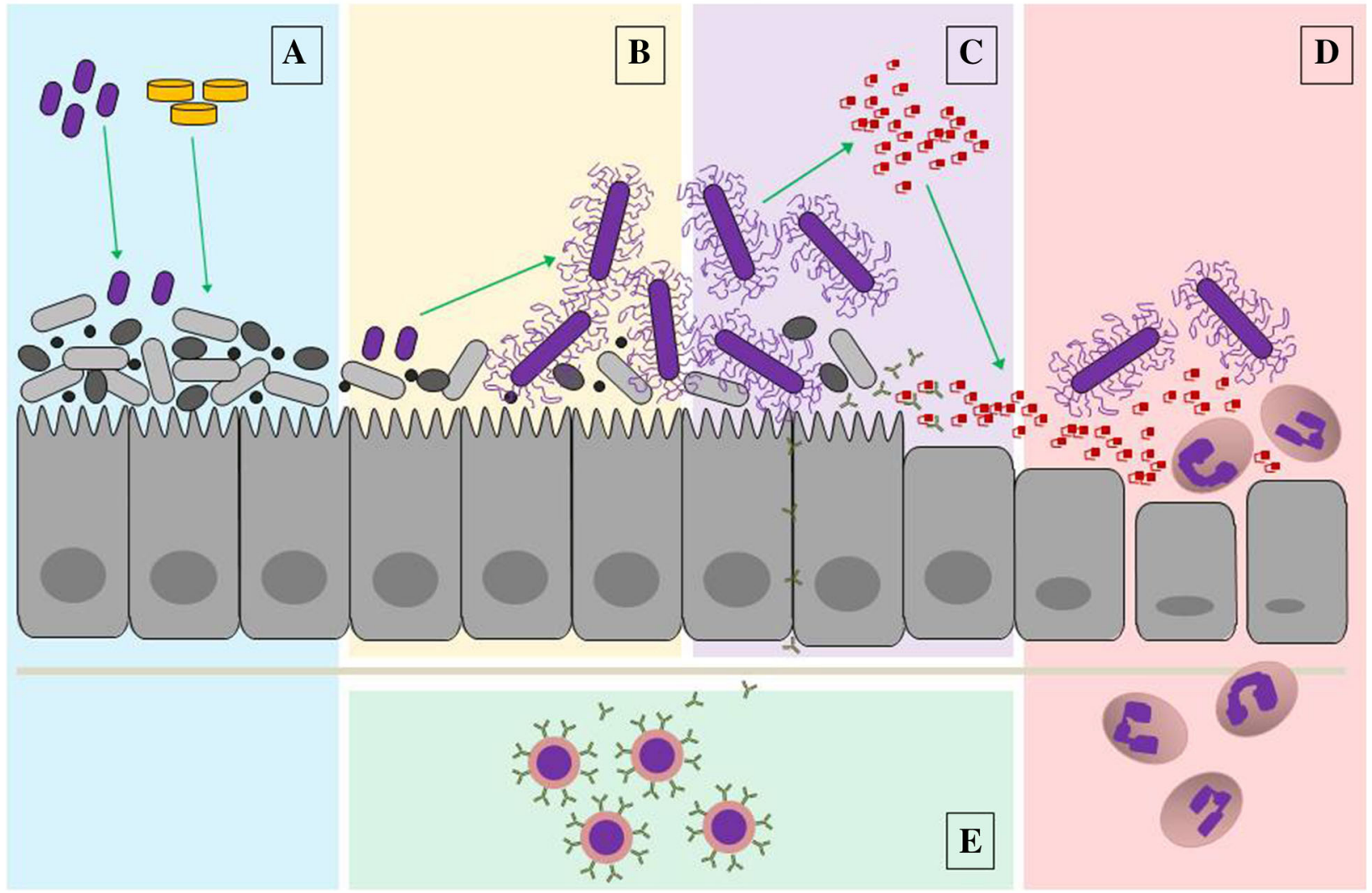

Fig. 1 Major events in Clostridium difficile infection pathogenesis as therapeutic targets of investigational anti-CDI treatments. $A$ Disruption of healthy gut microbiota and $C$. diffcile colonization - therapy aiming to protect or to restore the intestinal microbiota; $B C$. difficile germination and outgrowth-antibiotics and non-antibiotic agents targeting C. difficile; $C$ toxin secretion-toxin-neutralizing agents; $D$ toxin-mediated enterocyte damage and activation of the innate immune system - therapy aiming to alleviate intestinal

RNA synthesis, primarily used in the treatment of traveler's diarrhea and hepatic encephalopathy. It is considered to have very little and rather beneficial effect on the normal intestinal microbiota $[6,7]$, though its complete innocuousness in patients receiving long-term rifaximin treatment is questionable [8]. It was equally efficient as vancomycin in a hamster model of CDI, and-depending on the $C$. difficile strain used-similar or lower recurrence mucosa inflammation; $E$ adaptive immune system activation-active immunotherapy. The figure does not pretend to depict the entire process in its completeness but rather focuses on the main steps that are interfered with by the different treatment modalities detailed in the article. Important components of $C$. difficile pathogenesis and host defense (endosomes, cytoskeleton, dendritic cells, mucus layer, bile acids, etc.) are deliberately missing from the image

rates were observed after rifaximin withdrawal as compared to the vancomycin group [9]. There have been various retrospective and prospective clinical case series demonstrating its efficacy in first CDI episodes, as well as in recurrent and refractory CDI [10-13], but rifaximin failed to unmistakably demonstrate non-inferiority to vancomycin in a RCT [14]. Its somewhat higher resistance rates as compared to vancomycin and metronidazole-especially 


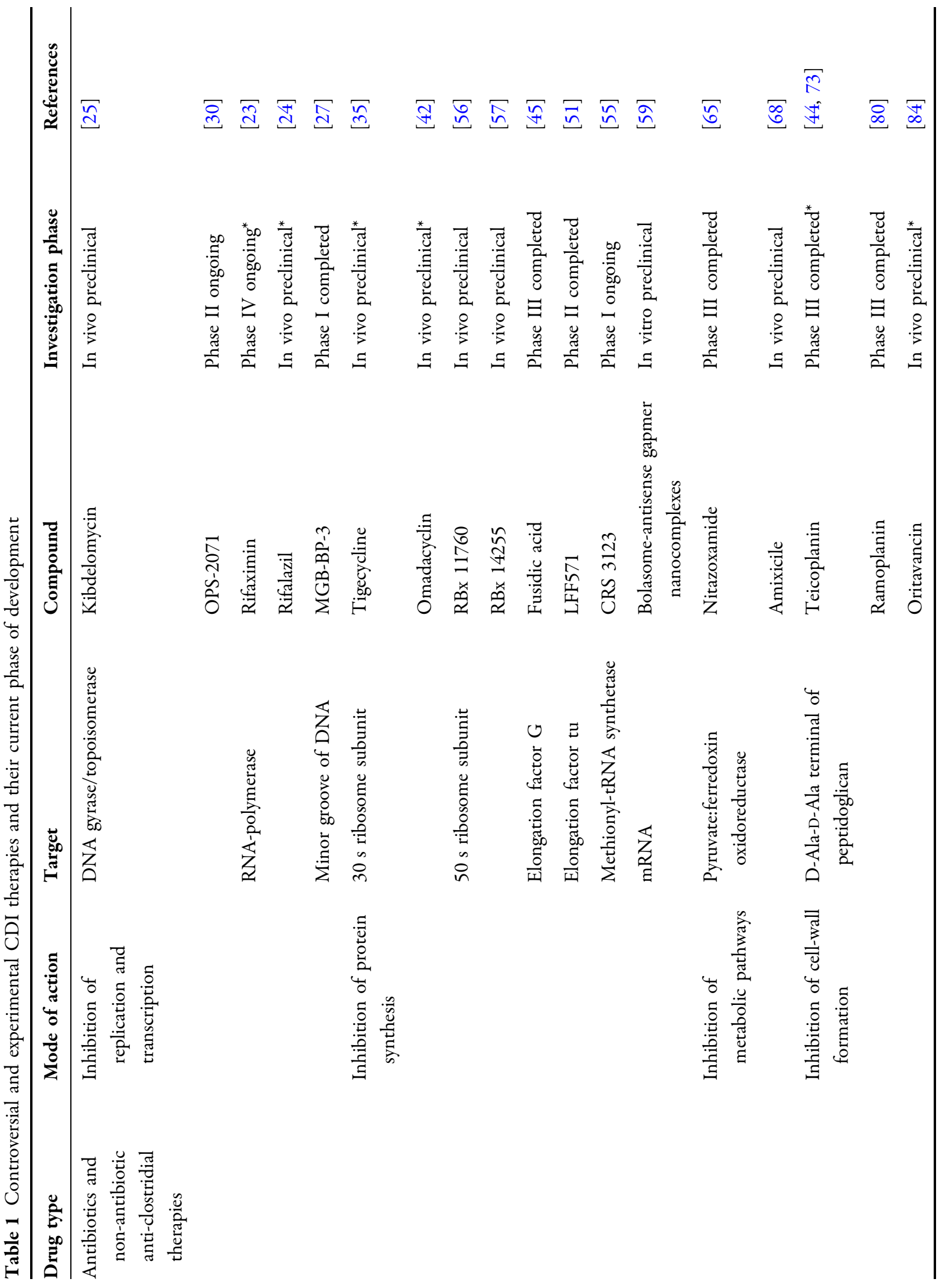




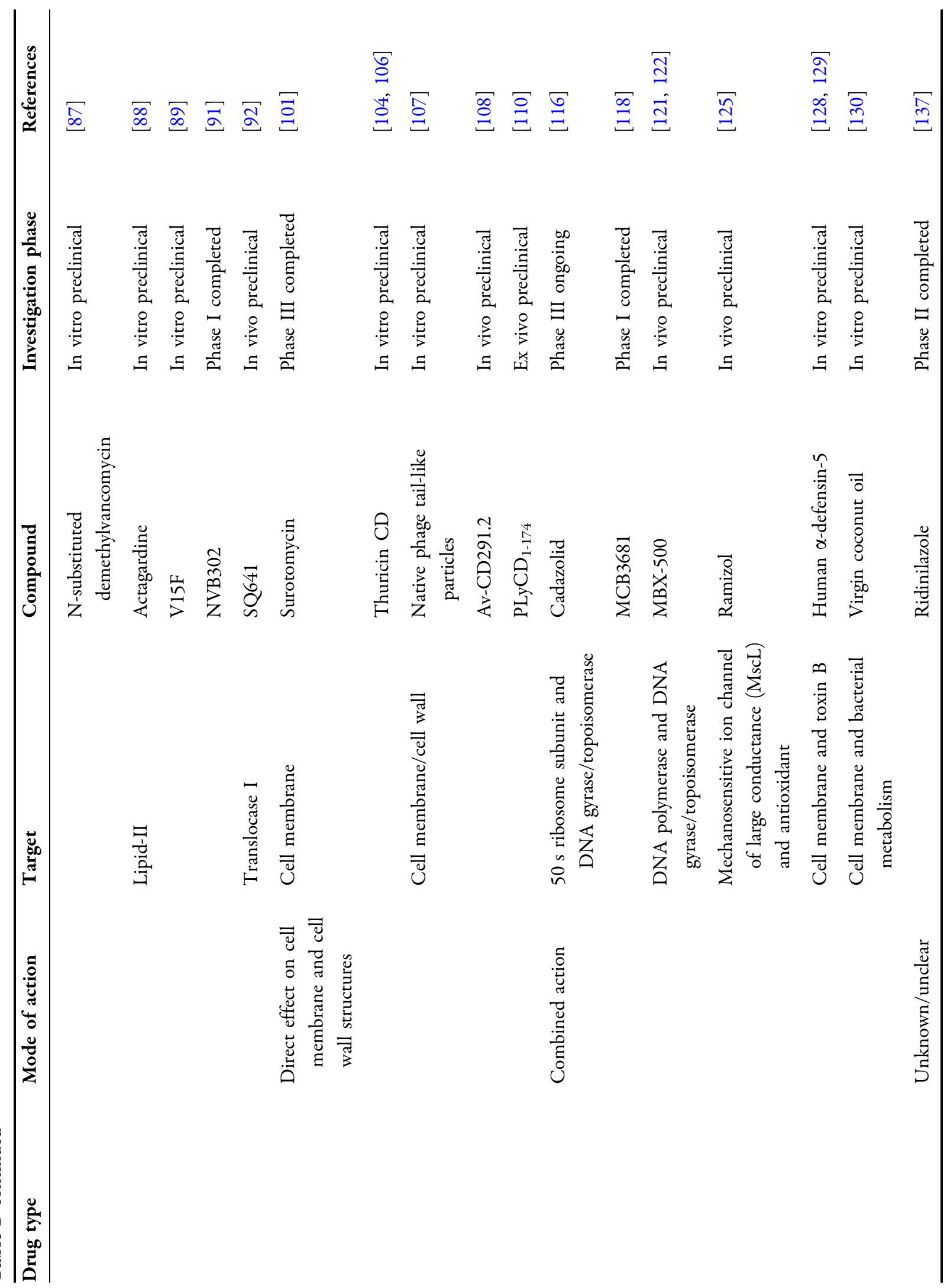




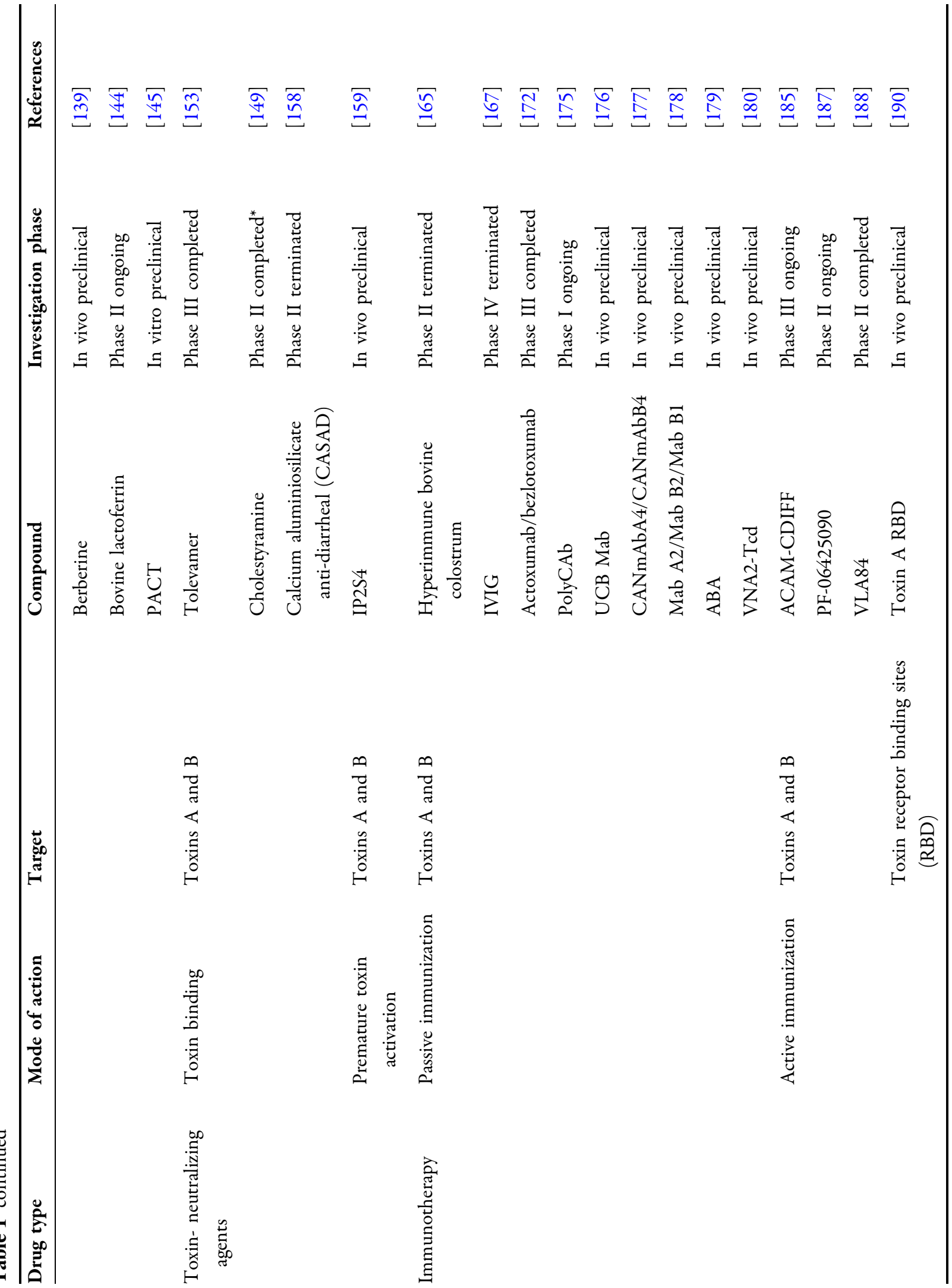




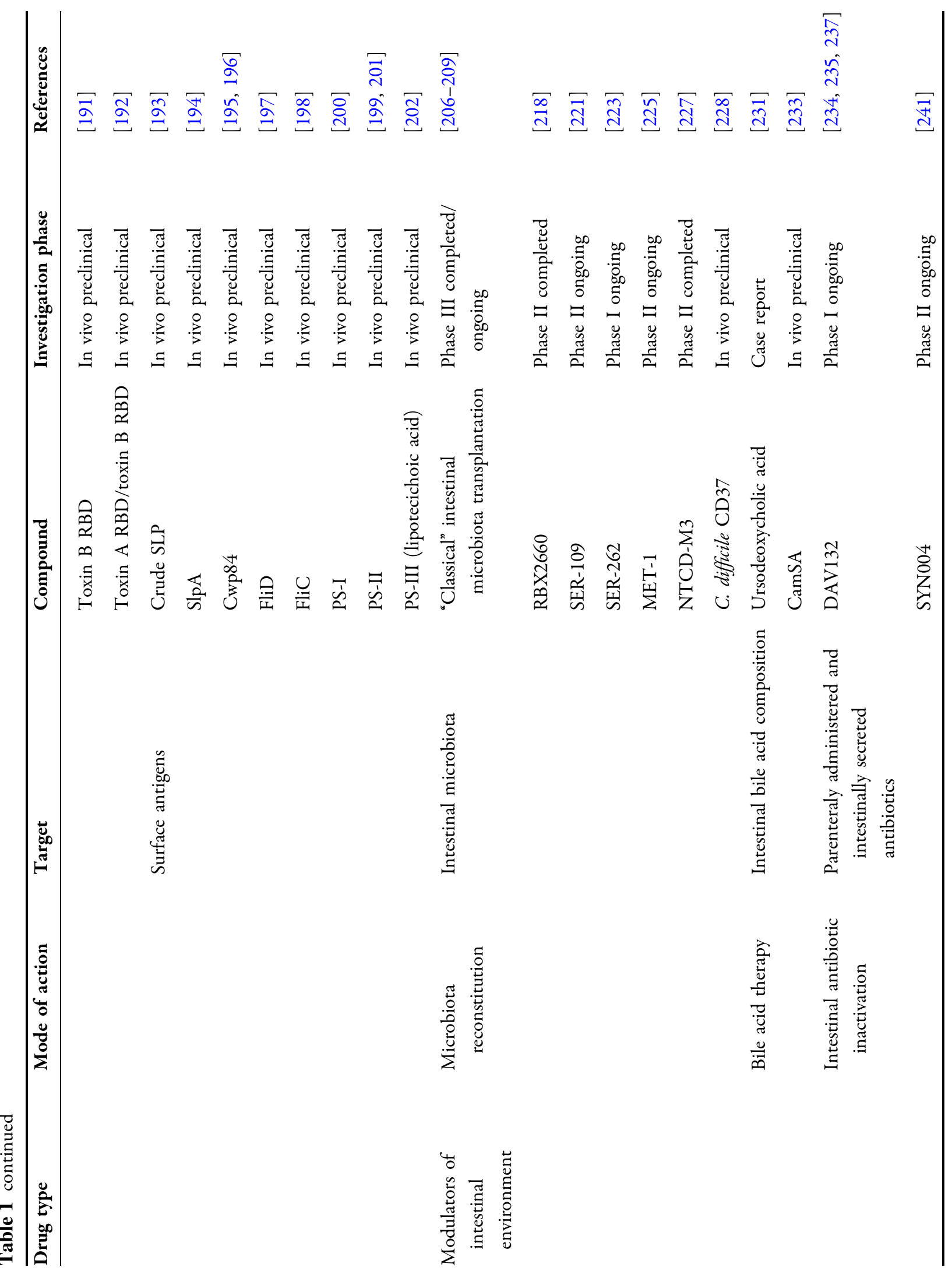




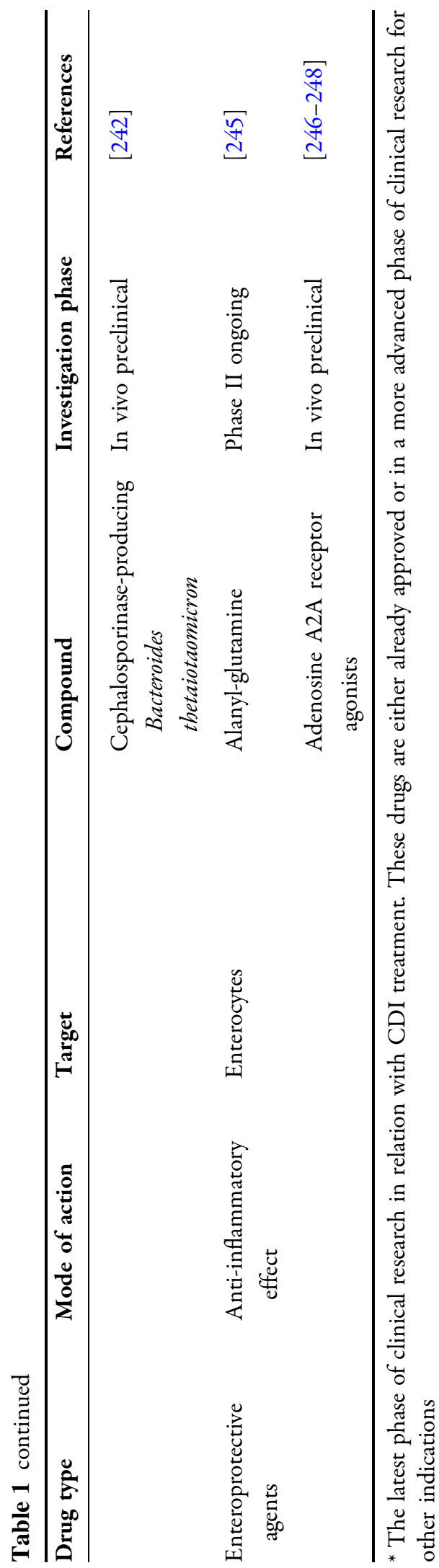

in binary toxin negative strains-and the possibility of resistance emergence during CDI therapy are additional issues of concern [15-19]. Today it may only be recommended as a "chaser" therapy after vancomycin treatment to reduce CDI recurrence risk [20], based on the results of case series $[19,21]$ and a small RCT [22]. A larger phase IV RCT to verify these data is currently recruiting participants [23].

Rifalazil is another rifamycin derivative, which conferred significantly lower mortality-both administered prophylactically and therapeutically-in a hamster CDI model, as compared to vancomycin [24]. However, no studies on its efficacy in human CDI have been published until now.

\section{Other Agents}

Kibdelomycin is a novel inhibitor of type II and IV topoisomerases developed by Merck, which possesses high in vitro activity against various C. difficile strains [25]. Encouraging results were obtained with it in a hamster model of CDI in terms of survival (80-100\%), bacterial elimination (2- to 5-log reduction of $C$. difficile counts) and a practically absent enteral absorption [25]. Upcoming phase I human trials have not yet been announced.

MGB Biopharma is developing a compound, MGB-BP-3, that interferes with the transcription of $C$. difficile DNA by binding directly to certain sequences on its minor groove [26]. It reduced both vegetative cell and spore count of intestinal C. difficile to a greater extent than vancomycin in an animal model [26], and it was well tolerated without raising major safety issues in a recent phase I human trial [27]. The initiation of a phase II trial with this compound is one of the major immediate objectives of the company [28].

OPS-2071 is a quinolone-based investigational compound under development by Otsuka Pharmaceutical. After two recently 
completed phase I trials [29], a phase II clinical trial is currently recruiting subjects to evaluate its efficacy and safety in CDI patients [30].

\section{Inhibitors of Protein Synthesis}

\section{Tetracyclines}

Tigecycline is the first member of the novel glycylcycline antibiotic family with a broad antimicrobial spectrum that inhibits protein synthesis by blocking the entry of aminoacyl-tRNA into the ribosome by binding to the 30S subunit [31]. Apart from possessing activity against a wide range of gram-positive and gram-negative bacteria, including multi-resistant strains, tigecycline inhibits both toxin production and sporulation of $C$. difficile in vitro [32, 33]. Although due to its wide spectrum tigecycline may alter the intestinal microbiota significantly, thus potentially facilitating primary and recurrent CDI [34], there are various reports about its efficacy as an anti-CDI agent in both animal studies [35] and the real-life clinical setting [36-40]. Solid evidence originating from RCTs, however, is still lacking. Consequently, the place of tigecycline in the CDI treatment hierarchy is still dubious, but it may be considered as a good substitute for other broad-spectrum antibiotics in appropriate cases when withdrawal of concomitant systemic antibiotic treatment at CDI diagnosis is not possible.

Omadacycline is a new aminomethylcycline antibiotic that binds to the tetracycline binding-site of the bacterial $30 \mathrm{~S}$ ribosome subunit, and it has considerable potency against gram-positive bacteria [41]. It also demonstrated high in vitro activity against $C$. difficile and was superior to vancomycin in terms of survival in a hamster model of CDI
[42]. Its clinical evaluation in human CDI has not yet been undertaken.

\section{Other Agents}

Fusidic acid is an inhibitor of elongation factor $\mathrm{G}$ that can act in a bacteriostatic or bactericidal manner depending on its concentration and exhibits good in vitro activity against $C$. difficile [43]. It was compared with vancomycin and metronidazole in an RCT [44] and with metronidazole in another one [45], showing comparable efficacy to its comparators in both studies. In one of these trials, however, significantly higher CDI recurrence rates were observed in patients receiving fusidic acid treatment than in the vancomycin and metronidazole groups [44]. Another concern with regards to fusidic acid is the relatively frequent emergence of resistant $C$. difficile strains during treatment, which also limits its routine use [46].

A semisynthetic thiopeptide antibiotic, LFF571, interferes with bacterial protein synthesis by inhibiting the delivery of aminoacyl-tRNA to the ribosome. Its average MIC values against $C$. difficile fall between the ones observed with fidaxomicin and vancomycin $[47,48]$, but it does not seem to be affected by mutations conferring resistance to these antibiotics [49]. It was tested against and proved superior to vancomycin in a hamster model of CDI in terms of survival and recurrence [50], and it was non-inferior to vancomycin in a phase II human study [51]. Novartis, the company behind LFF571, has not announced forthcoming phase III trials with this compound for the time being.

CRS3123 (previously REP3123) is an experimental drug against CDI with a novel mechanism of action, namely the inhibition of C. difficile methionyl-tRNA synthetase, which is an essential enzyme for bacterial protein 
synthesis. It proved to be highly active against C. difficile without significantly affecting major representatives of the normal intestinal microbiota [52, 53]. The superiority of CRS3123 to vancomycin and metronidazole was demonstrated in terms of inhibition of toxin formation and sporulation in vitro and also in terms of survival in an in vivo model [54]. According to the developer, Crestone Pharma, phase I studies with CRS3123 are currently underway [55].

RBx 11760, a biaryl oxazolidinone, was synthesized by Ranbaxy Research Laboratories. It inhibits sporulation and also has a considerable effect on $C$. difficile toxin production [56]. In an in vivo model of CDI the hamsters treated with RBx 11760 had longer survival than the ones receiving vancomycin or metronidazole [56].

$\mathrm{RBx} 14255$ is a new ketolide antibiotic developed by the same company as RBx 11760. It showed similar in vitro activity against $C$. difficile as vancomycin and metronidazole, but proved superior to both of them in terms of survival in an animal model [57].

Since Ranbaxy merged into Sun Pharmaceutical Industries in 2015, the future fate of these last two investigational compounds is unsure.

Antisense antibiotic therapy is a novel antimicrobial treatment method that aims to block the expression of key microbial genes by means of the binding of single-stranded oligomers to the corresponding complementary mRNA of the microorganism [58]. A recent study demonstrated the efficacy of this novel therapy against $C$. difficile in vitro [59]. The authors observed significant inhibition of bacterial growth with the addition of phosphorothioate gapmer antisense oligonucleotides complementary to
C. difficile mRNAs coding essential bacterial enzymes [59]. This revolutionary treatment method has been tested in various animal models of bacterial infections, but clinical trials have only been undertaken in viral infections until today [58].

\section{Inhibitors of Metabolic Pathways}

Nitazoxanide is a thiazolide antibiotic by Romark Laboratories, which interferes with the metabolism of anaerobic microorganisms by inhibiting the pyruvate:ferredoxin oxidoreductase [60]. This compound possesses potent antiparasitic and antiviral properties [61] and also showed potent activity against $C$. difficile in vitro, including strains with reduced metronidazole susceptibility $[62,63]$. Clinical trials comparing its efficacy with metronidazole (phase II) [64] and vancomycin (phase III) [65], however, were not conclusive, and the company presently pursues indications other than CDI for this drug [66].

Amixicile, a derivative of nitazoxanide with enhanced water solubility, synthesized at the University of Virginia, was comparable in terms of clinical cure to vancomycin and fidaxomicin in a mouse CDI model and resulted in lower recurrence rates than its comparators [67]. It does not appreciably affect intestinal microbiota, and though a considerable proportion of orally administered amixicile is intestinally absorbed, it seems to have a more favorable toxicity profile than nitazoxanide [68]. Human studies have not been undertaken with amixicile until today.

\section{Inhibitors of Cell-Wall Formation}

\section{Glycopeptides}

Glycopeptide antibiotics interfere with bacterial peptidoglycan synthesis and consequently 
inhibit cell wall formation. Apart from vancomycin there are a number of newer members of this family that have been tested in the treatment of CDI with promising results. Teicoplanin may be a good alternative to vancomycin treatment, although save for a recent observational study [69] no clinical evidence has been published on its use in the last 20 years. Theoretically teicoplanin may even be superior to vancomycin in this setting since it was reported to have lower MIC values for $C$. difficile [70, 71] and patients treated with teicoplanin had notoriously lower recurrence rates than the ones receiving vancomycin in the few RCTs conducted [44, 72, 73]. This difference was not statistically significant in any of these studies, but it is to be borne in mind that all of them had a rather small number of participants. A Cochrane meta-analysis, on the other hand, showed significantly better bacteriologic cure and a close-to-significant advantage in clinical cure in patients treated with teicoplanin as compared to the ones receiving vancomycin treatment [74]. Teicoplanin has had a licensed indication for CDI since 2013, and its oral formulation is available in many countries outside the USA [1].

Ramoplanin also has lower MICs against $C$. difficile than vancomycin [75] and maintains its activity even against strains with reduced vancomycin susceptibility [76]. Its sporicidal effect is superior to vancomycin as has been demonstrated both in vitro and in vivo $[77,78]$. A phase II study conducted more than 10 years ago is the only experience with ramoplanin in human subjects published [79], though according to the website of its current developer (Nanotherapeutics) a phase III RCT has already been completed and a phase IIb trial to evaluate its efficacy in CDI relapse prevention is imminent [80].
A novel lipoglycopeptide, oritavancin, showed 2-4 times lower MIC values against $C$. difficile as compared with vancomycin in an in vitro study [81]. It was tested against vancomycin in a human gut model with similar efficacy in the initial reduction of toxin levels, but oritavancin impeded recurrence after drug withdrawal to a greater extent than vancomycin $[82,83]$. In a hamster model it also proved superior to vancomycin in the prevention of CDI [84]. It seems that the capacity of oritavancin to avoid CDI recurrence lays in its adhesion to dormant $C$. difficile spores, promptly eliminating cells at an early stage of germination [85]. Human studies with oritavancin in the treatment of CDI are, however, still lacking.

Demethylvancomycin is a glycopeptid antibiotic clinically used in China since the 1960s [86]. Certain N-substituted demethylvancomycin derivatives showed enhanced activity as compared to vancomycin against $C$. difficile strains in an in vitro model [87], though these findings have not been verified in in vivo models.

\section{Other Agents}

A number of post-translationally modified bacteriocins (lantibiotics) have been subjects of research in the laboratories of Novacta Biosystems in recent years, which showed fair capacity to inhibit cell-wall synthesis. Actagardine, though it is not very active against $C$. difficile in itself, in combination with ramoplanin showed a potent synergistic effect against the majority of $C$. difficile strains tested in vitro [88], and a mutant variant of it, $\mathrm{V} 15 \mathrm{~F}$, seems to be twice as active as actagardine [89]. NVB302 proved to be non-inferior to vancomycin in a human gut model of CDI [90], and a successful phase I trial has also 
already been completed with this compound [91].

A synthetic analog of the naturally occurring nucleoside-based capuramycin, SQ641, targets translocase-1, an essential enzyme in bacterial cell-wall synthesis. It was originally intended to be an anti-tuberculosis agent, but since it had good in vitro activity against $C$. difficile it was tested in a mouse model of CDI and was superior to vancomycin in terms of 14-day survival [92]. The company behind this compound, Sequella, has not announced forthcoming human studies for the time being.

\section{Agents with Direct Effect on Cell Wall/Cell Membrane}

Surotomycin (MK-4261, previously CB-183,315) is a membrane-active cyclic lipopeptide, whose rights are owned by Merck since its acquisition of the original developing company, Cubist Pharmaceuticals, in 2015. It has potent bactericidal activity against both growing and stationary phase $C$. difficile [93]. It is also active against Enterococci [94] and disrupts intestinal microbiota only moderately $[95,96]$, although this may be sufficient to bring forward the overgrowth of extended-spectrum beta-lactamase-producing Klebsiella in surotomycin-treated patients [97]. On the other hand, the emergence of resistant $C$. difficile or Enterococcus strains during treatment is possible but fairly unlikely $[98,99]$. In a phase II clinical trial CDI recurrence rates were significantly lower and sustained clinical response rates were significantly higher in patients treated with surotomycin as compared to the vancomycin-treated control group [100]. However, the results of one of the two recently completed phase III trials [101] were recently made public, according to which the non-inferiority of surotomycin to vancomycin could not be demonstrated [102]. These disappointing results may be the explanation for the absence of surotomycin in Merck's latest research pipeline chart [103].

Thuricin CD, a sactibiotic produced by Bacillus thuringiensis, was proved to possess narrow-spectrum activity against $C$. difficile [104], having very little effect on the rest of the normal intestinal microbiota [105]. According to a recent study, the combination of Thuricin CD with other anticlostridial antibiotics may have a synergistic effect on biofilms formed by certain C. difficile strains [106].

Clostridium difficile produces so-called phage tail-like particles (PTLPs) that successfully eradicated $C$. difficile in an in vitro model [107]. In another study, administration of a genetically modified PTLP (Avidocin CD), called Av-CD291.2, successfully prevented $C$. difficile colonization in mice without interfering with the normal colonic flora [108]. The company behind Av-CD291.2, AvidBiotics, is planning to start human studies with this compound in the near future [109].

PLyCD $_{1-174}$ is the recombinantly expressed catalytic domain of a prophage endolysin identified in a $C$. difficile strain (CD630). It exerted potent lytic activity against $C$. difficile without significantly affecting other components of the intestinal microbiota in an ex vivo mouse model [110].

\section{Hybrid Antibiotics and Other Agents with Multiple Mechanisms of Action}

Cadazolid is a new fluoroquinoloneoxazolidinone antibiotic by Actelion, which exerts its antibacterial effect principally by the inhibition of protein synthesis and to a lesser degree also interferes with bacterial DNA synthesis [111]. Cadazolid not only has lower MICs against $C$. difficile than vancomycin and 
even fidaxomicin $[112,113]$, but it is also highly active against vancomycin resistant Enterococci, a major threat in vancomycin-treated patients, minimizing the risk of patient colonization by this much-dreaded bacteria [114]. This, combined with its potent activity against toxin formation and sporulation, makes it a promising new recruit among anticlostridial drugs. It performed well in a phase II trial as compared to vancomycin in first episodes or first recurrences of CDI [115], and it is currently being tested in two phase III clinical trials [116].

MCB3681, a novel fluoroquinolone-oxazolidinone antibiotic by Morphochem, also proved to possess excellent in vitro efficacy against $C$. difficile [117]. In a phase I study its water-soluble prodrug, MCB3837, was administered intravenously to healthy individuals and showed a marked reduction of gram-positive organisms without considerably affecting the gram-negative portion of intestinal microbiota [118]. Based on these data the Food and Drug Administration recently granted Fast Track designation to the compound, and the start of a phase II clinical trial with MCB3837 seems imminent [119].

MBX-500 (a.k.a compound 251D) is a novel hybrid antibiotic that binds to three different bacterial targets: its anilinuracil component acts as a DNA polymerase inhibitor, and its fluoroquinolone component blocks DNA topoisomerase and gyrase enzymes [120]. Its multiple-site action seems to make the rise of resistant strains during treatment less probable [120]. The in vivo efficacy of MBX-500 against C. difficile was demonstrated in at least three animal CDI models (hamsters [121], mice [121] and piglets [122]), but human studies have not yet been announced by its developer, Microbiotix.
Ramizol is the first member of a new antibiotic family that selectively targets the mechanosensitive ion channel of large conductance (MscL) in bacteria [123] and possesses potent antioxidant properties as well [124]. In a hamster model of CDI orally administered Ramizol conferred lower 28-day survival than vancomycin (57\% vs. $86 \%)$, and its spore-clearing capacity was also inferior to that of vancomycin (29-57\% vs. 100\%) [125]. The company behind it (Boulos and Cooper Pharmaceuticals), however, is currently working on a formulation of enhanced efficiency of this drug [125] and expects to initiate phase I clinical trials in 2017 [126].

Human $\alpha$-defensin 5 (HD5) is an enteric representative of membrane-active antimicrobial proteins and peptides (AMPs) produced in the small intestine by Paneth cells, forming an important, though not yet truly understood role in host-microbiota interactions [127]. Its role in C. difficile toxin-neutralization was suggested by one study [128], and direct C. difficile cell killing was observed in another one with physiological concentrations of HD5 [129]. Whether these characteristics of HD5 may be exploited in the fight against $C$. difficile is unclear.

Certain medium-chain fatty acids, such as lauric acid derived from virgin coconut oil, caused a significant inhibition of $C$. difficile growth in an in vitro study [130]. It is postulated that bacterial cell death is caused by the incorporation of these fatty acids in the bacterial cell membrane that brings forth a substantial change in its permeability as well as by a probable interference with cellular metabolism [131]. In vivo studies on the efficacy of virgin coconut oil or its derivatives in the prevention or treatment of CDI have not yet been undertaken. 


\section{Agents of Unknown/Unclear Mechanism of Action}

Ridinilazole (previously SMT19969) is a narrow-spectrum antibiotic with poor oral bioavailability that exhibits 2-17 times lower MIC values against $C$. difficile than vancomycin [132-134]. Its precise mechanism of action is not yet fully known, but it had a potent bactericidal effect on $C$. difficile, caused significant reduction of toxin levels and also demonstrated anti-inflammatory activity in vitro on human intestinal cells [135]. In a hamster model, better 28-day survival rates were observed in animals treated with ridinilazole than in the ones given vancomycin or fidaxomicin [136]. A phase II RCT was completed recently, where ridinilazole achieved the non-inferiority goal set in terms of clinical cure and was superior to vancomycin in terms of sustained clinical response after 30 days of follow-up [137]. Summit Therapeutics is currently preparing phase III RCTs with this compound [138].

Berberine is a natural substance already utilized in ancient Chinese folk medicine. The addition of berberine to vancomycin significantly improved mortality, prevented weight loss and decreased recurrence rates in a mouse model of CDI [139]. The authors speculated that berberine may counteract the deleterious effect of vancomycin on intestinal microbiota by inhibiting the expansion of Enterobacteriaceae. A recent in vitro study, however, showed a high berberine uptake of germinating $C$. difficile spores where it may reach elevated concentrations, inhibiting spore outgrowth on its own [140].

The bacteriostatic effect of bovine lactoferrin on Clostridium species has been known for more than 20 years [141]. As a biomarker for intestinal inflammation, its fecal concentrations seem to correlate with CDI severity [142]. Although it is postulated that lactoferrin exerts its bacteriostatic activity by acting as an iron-sequestering agent, in a recent mouse model of CDI the administration of iron-saturated-but not iron-depleted-bovine lactoferrin successfully inhibited $C$. difficile toxin production and delayed $C$. difficile outgrowth, without significantly affecting the rest of the intestinal microbiota [143]. A phase II RCT on its efficacy in the prevention of antibiotic-associated diarrhea in children is currently underway [144].

A completely new approach is being investigated under the aegis of Photobiotics Ltd., which aims to eradicate $C$. difficile by means of radical oxygen species produced by light-activated photosensitizers. The method, called Photodynamic Antimicrobial Chemotherapy (PACT), involves the activation of a light-sensitive dye (photosensitiser) by visible light that utilizes the received energy to generate radical species or singlet oxygen that, in turn, leads to cell death [145]. In an in vitro model, $99.9 \%$ of $C$. difficile colonies was eliminated by this method without causing appreciable harm to surrounding colon cells [145], but in vivo studies have not been conducted so far.

\section{TOXIN-NEUTRALIZING AGENTS}

Unlike the agents discussed above, toxin-neutralizing drugs aim not to eliminate C. difficile, but to prevent its cytotoxic effect on colonocytes. These agents either sequester or inactivate $C$. difficile toxins impeding them from reaching their target cells, hence preventing or alleviating the clinical manifestations of CDI. Their use as prophylactic or adjuvant therapy has a solid scientific basis, but since they have no effect on 
either vegetative $C$. difficile or its spores they do not prevent asymptomatic carriage and transmission.

\section{Toxin Binding}

Cholestyramine, an ion exchange resin usually used as a bile acid sequestrant, was the first one of the agents in this category to be tested more than 35 years ago [146]. There were various cases of recurrent CDI reported to respond to cholestyramine treatment by that time $[147,148]$, but the compound was never tested in any formal clinical trial. It does not seem to be suitable as an adjunct therapy to vancomycin, since it not only binds $C$. difficile toxins but the antibiotic as well [70]. Based on the encouraging results of a recent pilot study it was proposed to be used as primary CDI prophylaxis in patients receiving long-term systemic antibiotic treatment [149], but these findings will have to be confirmed in larger RCTs.

Tolevamer, a toxin-binding polymer, was a compound of great expectations during the first decade of this century [150, 151]. The initial enthusiasm, however, flagged considerably in light of more recent studies that proved its toxin neutralization capacity to be much lower than previously thought [152], and its clinical efficacy failed to match that of vancomycin or metronidazole in two clinical trials [153]. In these trials, however, CDI recurrence rates were significantly lower in the subset of patients that responded to tolevamer than in the subsets of responders in the vancomycin and the metronidazole group [154]. These data may adumbrate a potential use of tolevamer in CDI prophylaxis in the future, although Genzyme (now Sanofi Genzyme) indefinitely halted its development after the unsuccessful trials.

Calcium aluminosilicate anti-diarrheal (CASAD) is a naturally occurring clay known to possess considerable cation exchange absorbent properties. Its potential as a prophylactic agent in cancer-related diarrhea was recently investigated by Salient Pharmaceuticals, with inconclusive results $[155,156]$. However, because of its in vitro capacity to sequester $C$. difficile toxins [157], a phase II trial was initiated to investigate its efficacy as an adjuvant therapy of CDI, which was prematurely terminated because of slow enrollment [158].

\section{Premature Toxin-Activation}

Clostridium difficile takes advantage of a host cytosolic enzyme, inositol hexakisphosphate, that triggers an autocleavage process of the toxins once these become endocytosed into colonocytes, which results in their activation and the subsequent cytotoxic effect. A novel approach endeavors to combat CDI by the premature luminal activation of $C$. difficile toxins using an inositol hexakisphosphate analog (INS-5010) where some of the phosphate groups were substituted by sulfate groups for stability purposes. C. difficile-infected mice treated with this compound showed a significant reduction of histological signs of colitis as compared to control subjects [159]. The Swiss company developing INS-5010, Inositec $A G$, has not yet announced the initiation of human studies [160].

\section{Passive Immunization}

The potential of colostrum of pregnant cows immunized with $C$. difficile toxoids (hyperimmune bovine colostrum, HBC) to inhibit the cytotoxic and enterotoxic effect of C. difficile toxins has been known for more than 2 decades [161, 162]. Recently, it was proved to alleviate symptoms of CDI in gnotobiotic 
piglets without detectably affecting normal intestinal microbiota [163]. Whey protein concentrate derived from immunized cow milk was proved to be safe and well tolerated in human subjects with CDI as well [164]. A randomized phase II study comparing the efficacy of immune whey with metronidazole in the treatment of recurrent CDI showed similar clinical results to the two treatment modalities, but was terminated prematurely because of the bankruptcy of the sponsor (Novatreat Ltd.) [165].

The use of intravenous immunoglobuline (IVIG) in CDI has been subject to discussion for decades, but in the absence of evidence from RCTs its potential benefits remain controversial $[166,167]$. There are only two relatively small retrospective matched cohort studies published that compare the clinical efficacy of the addition of IVIG to conventional anti-clostridial treatment $[168,169]$. Neither of them found significant differences between the compared cohorts in the main clinical outcomes, though the authors of one of these studies point out that in their IVIG cohort there were significantly older patients with more severe CDI than in the control group [169].

The results of the first study on the efficacy of monoclonal antibodies against $C$. difficile toxin A (actoxumab, previously MK3415) and toxin B (bezlotoxumab, previously MK6072 and MDX1388) in a hamster model of CDI were published exactly 10 years ago [170]. In that study enhanced efficacy was observed with the combination of the two antibodies in terms of both recurrences and mortality. In a phase II trial with this combination (a.k.a. MK-3415A), the addition of the neutralizing antibodies to standard CDI treatment also significantly lowered recurrence rates [171]. However, although the efficacy of bezlotoxumab in preventing CDI recurrence was confirmed in two recently conducted phase III trials, its combination with actozumab, surprisingly, did not show any additional benefit in these studies [172]. Based on these results the US Food and Drug Administration (FDA) has very recently approved bezlotoxumab, and it will be available in the first quarter of 2017 [173].

There are several other companies and research entities as well focusing on monoclonal antibodies against $C$. difficile toxins. A mixture of anti-A and anti-B neutralizing antibodies of ovine origin (PolyCAB) is under research by MicroPharm, which showed a significant reduction of CDI recurrence in a hamster model [174]. Phase I trials with this product are currently ongoing [175]. UCB Pharma financed an investigation with UCB MAb, a mixture of three humanized antibodies (two against toxin $\mathrm{A}$ and one against toxin B) that proved to be superior in terms of survival after 28 days as compared to bezlotoxumab in hamsters [176]. Another mixture of humanized anti-A and anti-B antibodies (CANmAbA4 and CANmAbB4) by Emergent BioSolutions recently demonstrated excellent in vitro toxin neutralizing capacity and also conferred protection against clinical CDI in a hamster model [177]. BliNK Biomedical SAS, in turn, is developing a cocktail consisting of an anti-A and two anti-B monoclonal antibodies of entirely human origin (MAb A2 + MAb B1 + MAb B2) with very promising results in an animal study published last year [178]. A novel bispecific single-domain antibody, referred to as ABA, with binding domains for both toxin $\mathrm{A}$ and $\mathrm{B}$ demonstrated excellent toxin neutralization activity in vivo and achieved a 100\% survival in mice with fulminant CDI caused by the hypervirulent strain BI/NAP1/027 [179]. A modified version of ABA, VNA2-Tcd, has recently shown an outstanding protective 
capacity against CDI in another animal model [180]. Apart from these, various other monoclonal or single-domain antibodies against the toxins or other structural components (surface-layer proteins, flagella, etc.) of $C$. difficile are subjects of investigation currently, but none of these are in the clinical (and most of them not even in in vivo preclinical) phase of development yet [181].

\section{ACTIVE IMMUNOTHERAPY}

The preparation of the host immune system for a potential encounter with $C$. difficile and its toxins is the objective of this therapy. The most advanced vaccines elicit a potent immune response against toxins $\mathrm{A}$ and $\mathrm{B}$, but-similarly to toxin-neutralization-they do not lower colonization rates, and their preventive value manifests itself only on an individual level as the transmission risk remains unaffected. Other interesting vaccine candidates-which are in much earlier stages of development-targeting different surface components of $C$. difficile may offer certain advantages in this sense in the future.

\section{Toxoid and Recombinant Toxin-Based Vaccines}

ACAM-CDIFF is a toxoid vaccine against both toxin A and toxin B of $C$. difficile developed by Sanofi Pasteur. After positive immunological and clinical results obtained in a hamster model [182] and in two phase I studies [183], ACAM-CDIFF recently passed a phase II trial without any safety issues [184]. A phase III RCT with this vaccine is currently ongoing [185].

Pfizer is developing another toxoid vaccine (PF-06425090) with good results obtained in a phase I clinical trial [186], and two phase II trials with this product are currently under way in healthy adults [187].

VLA84 (a.k.a. IC84), a recombinant protein vaccine containing epitopes of toxin $A$ and toxin B developed by Valneva, showed positive results in a recent phase II trial in terms of safety, tolerability and immunogenicity in both younger adults and elderly volunteers [188]. The vaccine is soon to be tested in a phase III RCT, according to the company [189].

\section{DNA Vaccines}

DNA vaccines have the theoretical advantage over conventional vaccination of inducing not only humoral but also cellular immune response. The first DNA vaccine candidate for C. difficile encoded the receptor-binding site (RBD) of C. difficile toxin A [190]. Inoculated mice produced a potent antibody response to toxin A, and up to $100 \%$ survival was observed (depending on vaccine formulation and mouse strain) after challenge with a lethal dose of toxin A [190].

In another mouse model, apart from the RBD of toxin $\mathrm{A}$, the N-terminal enzymatic domain of toxin $\mathrm{B}$ also showed a positive antibody response [191]. The combination of the antibodies elicited by these two DNA vaccines conferred $100 \%$ protection against $C$. difficile in the experimental animals [191].

More recently, promising results were published with a novel DNA vaccine that contains plasmids encoding optimized RBDs of both toxin A and B of C. difficile [192]. The sera of immunized animals (mice and primates) showed potent toxin neutralization ability in vitro, and the combined vaccine provided a 50-90\% protection against a lethal dose of $C$. difficile spores in mice [192]. 


\section{Vaccines Against $C$. difficile Surface Antigens}

Although toxin-based vaccine candidates may successfully prevent toxin-mediated tissue damage and lessen the clinical manifestations of CDI, they do not prevent carrier status because they have no effect on $C$. difficile colonization. Vaccines targeting $C$. difficile surface antigens (proteins or carbohydrates) aim to offer a solution to this problem.

The surface layer protein (SLP) is the major surface antigen of $C$. difficile. It is made up of an outer layer formed by low-molecular-weight SLP (LMW-SLP) and an inner layer formed by high-molecular-weight SLP (HMW-SLP). These two proteins are created from a common precursor molecule (SlpA) that undergoes enzymatic cleavage by a protease (Cwp84) once SlpA reaches the cell surface. Intranasal or intraperitoneal administration of crude SLP (containing both HMW-SLP and LMW-SLP) conferred only moderate protection against a lethal C. difficile challenge in hamsters and mice [193]. Intra-rectal vaccination with the precursor protein SlpA in another animal study resulted in slightly more favorable results, as it significantly decreased the colonization level in the vaccinated mouse group, though it also failed to provide significant benefit in terms of survival [194]. The immunogenicity and protective ability of the protease Cwp84 have also been investigated in hamsters: rectally administered Cwp84 partially inhibited intestinal colonization and significantly increased the survival of hamsters challenged with $C$. difficile in one study [195], and similar survival rates (40\%) were observed in another one with the intragastric administration of the same vaccine encapsulated in pectin beads [196].
Elements of $C$. difficile flagellum can also be found among potential future vaccine candidates. Recombinant flagellar cap protein (FliD) in combination with either Cwp84 or a mix of other flagellar proteins administered rectally to mice resulted in significantly lower colonization rates as compared to control animals [197]. Intraperitoneal vaccination with recombinant flagellin (FliC), on the other hand, significantly improved survival in mice and hamsters infected with $C$. difficile in a recent study, while leaving the rest of the intestinal microbiota apparently intact [198].

All three known surface polysaccharides of C. difficile have been proved to be capable of eliciting a certain level of immune response. PS-I was first detected on the hypervirulent $C$. difficile strain 027 but it is not specific to this ribotype [199]. Conjugates of either synthetic PS-I or its disaccharide minimal immunogenic epitope with the diphtheria toxin variant $\mathrm{CRM}_{197}$ proved immunogenic in mice [200]. Another murine model demonstrated the immunogenicity of a conjugate vaccine of a synthetic hexasaccharide epitope of PS-II with $\mathrm{CRM}_{197}$ [201], and PS-II-specific immune response was observed in swine as well after being vaccinated with a non-adjuvanted PSI/ PSII preparation [199]. In a recent study a conjugate vaccine of lipoteichoic acid (LTA, a.k.a. PS-III) and $\mathrm{CRM}_{197}$ not only evoked antigen-specific immune response in a mouse model, but also significantly inhibited intestinal C. difficile colonization [202].

There are a number of other potential $C$. difficile vaccine candidates in the preclinical phase of investigation that may be tested in the clinical setting as well in the forthcoming years [203, 204]. 


\section{RESTORATION AND MODULATION OF THE INTESTINAL MICROBIOTA}

Preservation and/or restoration of colonization resistance of the intestinal microbiota is the primary objective of the following therapies with subsequent protection against toxigenic $C$. difficile colonization or its elimination from the colon. Among these methods there are some that endeavor to offer the most complete solution for the problem of CDI, aiming to achieve clinical cure and the prevention of carriage, transmission and recurrences all at once.

\section{Microbiota Restoration}

The microbiota-restoring therapy par excellence is intestinal microbiota transplantation, which has been living a true renaissance in the last years. Its excellent clinical efficacy is further upheld by the observation that host intestinal microbiota composition and diversity are intimately linked to CDI severity and recurrence risk [205].

That the restoration of an impaired intestinal microbiota by transplanting feces of a healthy individual may effectively cure CDI and prevent recurrences is not questioned any more $[1,20]$. Its efficacy was proven in two already published phase II RCTs [206, 207], and another phase II RCT performed on pediatric patients has also recently been completed [208], whose results are not yet available. Beside these completed studies there are various ongoing phase II and III RCTs with this treatment method [209].

With the demonstration that the efficacy of previously recollected frozen and freshly harvested microbiota have the same efficacy, intestinal microbiota transplantation has become a lot less cumbersome than before $[210,211]$. However, the manipulation of feces and classical enteral administration methods (i.e., by nasogastric tube, rectal enemas or via colonoscopy) are not only laborious, but make this procedure rather unattractive for physicians and patients alike [212-214]. For this reason there are a number of efforts being made to enhance feasibility and social acceptance of this highly efficient therapy. Oral administration of capsulized intestinal microbiota is one of the pioneer solutions for the above problem [215]. The elevated number of microbiota-containing capsules to be administered, though, is a major drawback of this method, which may be improved by submitting microbiota to lyophilization instead of simple freezing $[216,217]$.

RBX2660 is a commercially available, standardized microbiota suspension prepared from human stool (Rebiotix Inc.) that demonstrated its efficacy in a multicenter open-label phase II study [218]. A phase IIb RCT with this product has recently completed enrollment, and if its results are favorable RBX2660 is intended to enter phase III [219].

Seres Therapeutics has recently developed SER-109, which contains around 50 species of feces-derived Firmicutes spores after the elimination of the rest of the microbiota with ethanol. In an uncontrolled study, it was administered orally in an encapsulated form to 30 patients with multiple CDI recurrences after an appropriate response of standard of care antibiotic treatment, and no further recurrences were observed during the 8-week-long follow-up in $96.7 \%$ of the subjects [220]. A phase II trial to compare its efficacy with placebo is currently recruiting participants [221]. The same laboratory is investigating another microbial preparation comprised of spores of 12 different bacterial species (SER-262) meant to prevent recurrence after first CDI episodes [222]. An ongoing phase Ib 
RCT is currently evaluating the efficacy of this product as compared to placebo [223].

MET-1 (Microbial Ecosystem Therapeutic-1) is a defined intestinal bacterial culture originating from a single donor. Two patients with recurrent CDI who were treated with this product experienced clinical cure in 2-3 days and remained recurrence free for the 6 following months [224]. An open-label pilot study is about to be initiated to demonstrate its efficacy in recurrent CDI in comparison with vancomycin [225].

The administration of nontoxigenic $C$. difficile strains is another original approach to prevent colonization by toxigenic $C$. difficile. The most advanced research is being done with the nontoxigenic $C$. difficile strain M3 (NTCD-M3, a.k.a. VP20621), with encouraging results in animals [226] and in a recent phase II placebo-controlled human trial as well [227]. Another nontoxigenic strain, CD37, also provided significant protection against CDI in a mouse model as observed by less weight loss and less mortality in mice treated as compared to untreated animals [228].

\section{Bile Acid Therapy}

The bile acid composition of the gut has an important role in the upholding of colonization resistance, as certain secondary bile acids formed by members of a healthy microbiota have an important role in the inhibition of $C$. difficile spore germination [229]. The loss of this effect due to the disruption of intestinal microbiota by broad-spectrum antibiotic treatment is a key factor in C. difficile outgrowth, potentially leading to clinical CDI [230]. A secondary bile acid, ursodeoxycholic acid, was recently proved beneficial in a case of refractory C. difficile-associated pouchitis [231], but further evaluation of this compound in this setting has not yet been undertaken. A taurocholate analog, CamSA, is a potent in vitro inhibitor of $C$. difficile germination [232] that successfully prevented CDI in mice in a dose-dependent manner [233]. Whether secondary bile acids or their analogs will play a role in CDI prevention or if they can also be beneficial as adjunct in CDI treatment is still unknown.

\section{Intestinal Antibiotic Inactivators}

CDI risk is intimately linked to the damage systemic antibiotic therapy exerts on the intestinal microbiota. Methods to avoid this deleterious side effect by the inactivation of antibiotics that reach the colon lumen promise not less than the elimination of this single major risk factor in cases when antibiotic treatment is inevitable.

DAV132 is an activated-charcoal-based product with enteric coating that successfully adsorbs antibiotics such as amoxicillin or moxifloxacin that reach the proximal colon $[234,235]$. This compound, developed by DaVolterra, proved to prevent moxifloxacin-induced CDI in an animal model [236] and was demonstrated to be safe and efficient in humans as well, in two phase I RCTs $[234,235]$. A dose-finding phase I RCT is currently recruiting participants [237], and a phase II trial in patients at risk of CDI is already being prepared by the company [238].

The capacity of orally administered beta-lactamase enzymes to inactivate parenterally administered beta lactam antibiotics secreted into the gut is the basis of another approach to prevent antibiotic-induced microbiota damage [239]. SYN-004 is a recombinant beta-lactamase developed by Synthetic Biologics that efficiently inactivated intravenous ceftriaxone in the gut of dogs 
without interfering with serum antibiotic levels [240]. Its efficacy and good tolerability were recently proved by two phase I RCTs [241], and three phase II trials are currently underway with this product [241].

The same effect is sought by the research group that colonized the gut of mice with cephalosporinase-producing Bacteroides thetaiotaomicron to evaluate its efficacy in inactivating the intestinally excreted portion of subcutaneously administered ceftriaxone [242]. The investigators observed that the cephalosporinase produced by $B$. thetaiotaomicron successfully preserved normal intestinal microbiota and prevented colonization by both $C$. difficile and vancomycin-resistant Enterococcus in treated mice.

\section{ENTEROPROTECTIVE AGENTS}

These compounds are not explicitly anti-clostridial agents, but seek to alleviate the inflammation of the colon in CDI patients, hence decreasing morbidity and improving survival of severely ill patients.

Glutamine supplementation is traditionally used to preserve and/or restore intestinal mucosal integrity in patients with prolonged parenteral nutrition, gastric ulcer, chemotherapy, radiotherapy or intestinal surgery, among other conditions. Alanyl-glutamine is a bipeptide derived from glutamine with enhanced stability and water solubility. Its capacity both in vitro and in vivo to counteract cytotoxic activity of $C$. difficile toxins $\mathrm{A}$ and $\mathrm{B}$ was demonstrated in different studies [243, 244]. In a mouse CDI model the addition of alanyl-glutamine to vancomycin treatment resulted in improved survival as compared to vancomycin treatment alone
[244]. There is currently a phase II human trial underway at the University of Virginia to test the efficacy of alanyl-glutamine supplementation in reducing mortality and recurrences in CDI patients receiving standard anticlostridial treatment [245].

The activation of adenosine $\mathrm{A} 2 \mathrm{~A}$ receptors in macrophages and neutrophils has anti-inflammatory and tissue-protective effects by regulating the secretion of pro- and anti-inflammatory cytokins. The combination treatment with vancomycin and an adenosine A2A receptor agonist (ATL370 or ATL1222) resulted in less weight loss and better survival in a mouse CDI model as compared with vancomycin monotherapy [246]. Another adenosine A2A receptor agonist, ATL313, successfully prevented major damage of murine ileal mucosa induced by $C$. difficile toxin A [247]. The combination of alanyl-glutamine and an ATL370 also efficiently reversed histopathologic damage caused by toxin A in another animal study [248]. No human studies have been conducted with these products for the time being.

\section{CONCLUDING REMARKS}

The number of potential therapies for CDI has been growing steadily recently, and this trend may continue for some years, as both the incidence and severity of $C$. difficile keep increasing, and current therapeutics cannot offer a definite solution for this situation. Antibiotic surveillance programs and more directed anti-clostridial antibiotics have been demonstrated to be useful, but the steadily increasing number of susceptible hosts (immunocompromised patients, elderly, etc.) may prove these efforts insufficient to halt the epidemic. 
It seems clear that none of the described novel treatment methods will be able to deliver the ultimate solution for CDI single-handedly, since none of them can address all the components of the compound objective of CDI management, that is, primary prophylaxis, cure and prevention of recurrences. However, the more prophylactic and therapeutic tools are available the more efficient anti-CDI strategies can be tailored for different patient populations in different geographical areas with varying $C$. difficile prevalence.

Certainly, the greatest impact on CDI prevalence is to be expected from measures that aim to prevent the infection by means of active immunization or by protecting the healthy intestinal microbiota. On the other hand, the prompt restoration of a damaged microbiota and potent and narrow spectrum anti-clostridial antibiotics may guarantee a quicker recovery in established CDI, hence diminishing transmission and recurrence risk alike. At the same time, anti-toxin and anti-inflammatory treatment may improve the clinical outcome in severe and/or complicated CDI. As new therapeutic agents appear on the market, efforts shall be made to find the optimal way to combine them in a way that minimizes incidence and horizontal transmission, maximizes cure rates and keeps recurrences at a minimum.

\section{ACKNOWLEDGEMENTS}

No funding or sponsorship was received for this study or publication of this article. All named authors meet the International Committee of Medical Journal Editors (ICMJE) criteria for authorship for this manuscript, take responsibility for the integrity of the work as a whole and have given final approval to the version to be published.

Disclosures. Csaba Fehér, Alex Soriano and Josep Mensa declare that they have no conflicts of interest.

Compliance with Ethics Guidelines. This article is based on previously conducted studies and does not involve any new studies of human or animal subjects performed by any of the authors.

Data Availability. Data sharing is not applicable to this article as no data sets were generated or analyzed during the current study.

Open Access. This article is distributed under the terms of the Creative Commons Attribution-NonCommercial 4.0 International License (http://creativecommons.org/licenses/ by-nc/4.0/), which permits any noncommercial use, distribution, and reproduction in any medium, provided you give appropriate credit to the original author(s) and the source, provide a link to the Creative Commons license, and indicate if changes were made.

\section{REFERENCES}

1. Debast SB, Bauer MP, Kuijper EJ. European Society of Clinical Microbiology and Infectious Diseases: update of the treatment guidance document for Clostridium difficile infection. Clin Microbiol Infect. 2014;20(Suppl 2):1-26. doi:10.1111/1469-0691. 12418.

2. Cohen SH, Gerding DN, Johnson S, Kelly CP, Loo VG, McDonald LC, et al. Clinical practice guidelines for Clostridium difficile infection in adults: 2010 update by the society for healthcare epidemiology of America (SHEA) and the infectious diseases society of America (IDSA). Infect Control Hosp Epidemiol. 2010;31:431-55. doi:10.1086/651706.

3. Cornely OA, Nathwani D, Ivanescu C, Odufowora-Sita O, Retsa P, Odeyemi IAO. Clinical 
efficacy of fidaxomicin compared with vancomycin and metronidazole in Clostridium difficile infections: a meta-analysis and indirect treatment comparison. J Antimicrob Chemother. 2014;69:2892-900. doi:10.1093/jac/dku261.

4. Cornely OA, Crook DW, Esposito R, Poirier A, Somero MS, Weiss $\mathrm{K}$, et al. Fidaxomicin versus vancomycin for infection with Clostridium difficile in Europe, Canada, and the USA: a double-blind, non-inferiority, randomised controlled trial. Lancet. 2012;12:281-9. doi:10.1016/S01406736(11)61514-6.WEB-ONLY.

5. Louie TJ, Miller MA, Mullane K, Weiss K, Lentnek A, Golan Y, et al. Fidaxomicin versus vancomycin for Clostridium difficile infection. $\mathrm{N}$ Engl $\mathrm{J}$ Med. 2011;364:422-31.

6. Ponziani FR, Scaldaferri F, Petito V, Paroni Sterbini F, Pecere S, Lopetuso LR, et al. The Role of antibiotics in gut microbiota modulation: the eubiotic effects of rifaximin. Dig Dis. 2016;34:269-78. doi:10.1159/000443361.

7. Neff GW, Jones M, Jonas M, Ravinuthala R, Novick $\mathrm{D}$, Kaiser TE, et al. Lack of Clostridium difficile infection in patients treated with rifaximin for hepatic encephalopathy: a retrospective analysis. J Clin Gastroenterol. 2013;47:188-92. doi:10.1097/ MCG.0b013e318276be13.

8. Zullo A, Ridola L, Hassan C. Rifaximin therapy and Clostridium difficile infection. A note of caution. J Clin Gastroenterol. 2013;47:737-8.

9. Kokkotou E, Moss AC, Michos A, Espinoza D, Cloud JW, Mustafa $\mathrm{N}$, et al. Comparative efficacies of rifaximin and vancomycin for treatment of Clostridium difficile-associated diarrhea and prevention of disease recurrence in hamsters. Antimicrob Agents Chemother. 2008;52:1121-6. doi:10.1128/AAC.01143-07.

10. Basu PP, Dinani A, Rayapudi K, Pacana T, Shah NJ, Hampole $\mathrm{H}$, et al. Rifaximin therapy for metronidazole-unresponsive Clostridium difficile infection: a prospective pilot trial. Therap Adv Gastroenterol. 2010;3:221-5. doi:10.1177/ $1756283 \times 10372985$.

11. Garey KW, Jiang Z-D, Bellard A, Dupont HL. Rifaximin in treatment of recurrent Clostridium difficile-associated diarrhea: an uncontrolled pilot study. J Clin Gastroenterol. 2009;43:91-3. doi:10. 1097/MCG.0b013e31814a4e97.

12. Tannous G, Neff G, Kemmer N. Therapeutic success of rifaximin for Clostridium difficile infection refractory to metronidazole and vancomycin. Case Rep Gastroenterol. 2010;4:404-9. doi:10.1159/ 000320685.
13. Rubin DT, Sohi S, Glathar M, Thomas T, Yadron N, Surma BL. Rifaximin is effective for the treatment of Clostridium difficile-associated diarrhea: results of an open-label pilot study. Gastroenterol Res Pract. 2011;2011:106978. doi:10.1155/2011/106978.

14. Pardi DS, Brennan R, Spinnell $M$, Gareca MG, Greenberg E, Tian W, et al. The efficacy and safety of rifaximin vs. vancomycin in the treatment of mild to moderate $C$. difficile infection: a randomized double-blind active comparator trial. Gastroenterology 2012;142:S-599. doi:10.1016/ S0016-5085(12)62296-3.

15. Marchese A, Salerno A, Pesce A, Debbia E a, Schito GC. In vitro activity of rifaximin, metronidazole and vancomycin against Clostridium difficile and the rate of selection of spontaneously resistant mutants against representative anaerobic and aerobic bacteria, including ammonia-producing species. Chemotherapy. 2000;46:253-66. doi:10.1159/ 000007297.

16. Jiang Z-D, DuPont HL, La Rocco M, Garey KW. In vitro susceptibility of Clostridium difficile to rifaximin and rifampin in 359 consecutive isolates at a university hospital in Houston. Texas. J Clin Pathol. 2010;63:355-8. doi:10.1136/jcp.2009. 071688 .

17. Liao CH, Ko WC, Lu JJ, Hsueh PR. Characterizations of clinical isolates of Clostridium difficile by toxin genotypes and by susceptibility to 12 antimicrobial agents, including fidaxomicin (OPT-80) and rifaximin: a multicenter study in Taiwan. Antimicrob Agents Chemother. 2012;56:3943-9. doi:10.1128/AAC.00191-12.

18. Carman RJ, Boone JH, Grover $\mathrm{H}$, Wickham $\mathrm{KN}$, Chen L. In vivo selection of rifamycin-resistant Clostridium difficile during rifaximin therapy. Antimicrob Agents Chemother. 2012;56:6019-20. doi:10.1128/AAC.00974-12.

19. Johnson S, Schriever C, Galang M, Kelly CP, Gerding DN. Interruption of recurrent Clostridium difficile-associated diarrhea episodes by serial therapy with vancomycin and rifaximin. Clin Infect Dis. 2007;44:846-8. doi:10.1086/511870.

20. Trubiano JA, Cheng AC, Korman TM, Roder C, Campbell A, May MLA, et al. Australasian Society of Infectious Diseases updated guidelines for the management of Clostridium difficile infection in adults and children in Australia and New Zealand. Intern Med J. 2016;46:479-93. doi:10.1111/imj. 13027.

21. Johnson S, Schriever C, Patel U, Patel T, Hecht DW, Gerding DN. Rifaximin Redux: treatment of recurrent Clostridium difficile infections with Rifaximin immediately post-vancomycin 
treatment. Anaerobe. 2009;15:290-1. doi:10.1016/j. anaerobe.2009.08.004.

22. Garey KW, Ghantoji SS, Shah DN, Habib M, Arora $\mathrm{V}$, Jiang $\mathrm{ZD}$, et al. A randomized, double-blind, placebo-controlled pilot study to assess the ability of rifaximin to prevent recurrent diarrhoea in patients with Clostridium difficile infection. J Antimicrob Chemother. 2011;66:2850-5. doi:10. 1093/jac/dkr377.

23. Rifaximin for Preventing Relapse of Clostridium Associated Diarrhoea (RAPID) ClinicalTrials.gov Identifier: NCT01670149. https://clinicaltrials.gov/ ct2/show/NCT01670149?term=rifaximin+clostridiu m\&rank=1. Accessed 22 Sep 2016.

24. Anton PM, O'Brien M, Kokkotou E, Eisenstein B, Michaelis A, Rothstein D, et al. Rifalazil treats and prevents relapse of Clostridium difficile-associated diarrhea in hamsters. Antimicrob Agents Chemother. 2004;48:3975-9. doi:10.1128/AAC.48. 10.3975-3979.2004.

25. Miesel L, Hecht DW, Osmolski JR, Gerding D, Flattery A, Li F, et al. Kibdelomycin is a potent and selective agent against toxigenic Clostridium difficile. Antimicrob Agents Chemother. 2014;58:2387-92. doi:10.1128/AAC.00021-14.

26. Firmin D. Bringing true novelty to the anti-infective space. SMi's 17th Annu Conf Superbugs Superdrugs, London: 2015.

27. Ravic M, Firmin D, Sahgal O, van der Berg F, Suckling C, Hunter I. A single-centre, double-blind, placebo-controlled study in healthy men to assess the safety and tolerability of single and repeated ascending doses of MGB-BP-3, a new class of antibacterial agent. Boston: ASM Microbe Meet; 2016.

28. Programmes Overview. http://www.mgbbiopharma.com/programs-overview-2/. Accessed 12 Oct 2016.

29. ClinicalTrials.org. https://clinicaltrials.gov/ct2/ results?term=ops-2071+phase $+1 \&$ Search=Search. Accessed 4 Oct 2016.

30. Otsuka Group-Pipeline Information 2016. https:// www.otsuka.com/en/rd/pharmaceuticals/pipeline/ pdf.php?financial=442. Accessed 9 Sep 2016.

31. Nathwani D. Tigecycline: clinical evidence and formulary positioning. Int $\mathrm{J}$ Antimicrob Agents. 2005;25:185-92. doi:10.1016/j.ijantimicag.2004.11. 006.

32. Aldape MJ, Heeney DD, Bryant AE, Stevens DL. Tigecycline suppresses toxin A and B production and sporulation in Clostridium difficile.
J Antimicrob Chemother. 2015;70:153-9. doi:10. 1093/jac/dku325.

33. Garneau JR, Valiquette L, Fortier L-C. Prevention of Clostridium difficile spore formation by sub-inhibitory concentrations of tigecycline and piperacillin/tazobactam. BMC Infect Dis. 2014;14:29. doi:10.1186/1471-2334-14-29.

34. Bassis CM, Theriot CM, Young VB. Alteration of the Murine gastrointestinal microbiota by tigecycline leads to increased susceptibility to Clostridium difficile infection. Antimicrob Agents Chemother. 2014;58:2767-74. doi:10.1128/AAC.02262-13.

35. Kim HB, Zhang Q, Sun X, Beamer G, Wang Y, Tzipori $S$. Beneficial effect of oral tigecycline treatment on Clostridium difficile infection in gnotobiotic piglets. Antimicrob Agents Chemother. 2014;58:7560-4. doi:10.1128/AAC.03447-14.

36. Kundrapu S, Hurless K, Sunkesula VCK, Tomas M, Donskey CJ. Tigecycline exhibits inhibitory activity against Clostridium difficile in the intestinal tract of hospitalised patients. Int J Antimicrob Agents. 2015;45:424-6. doi:10.1016/j.ijantimicag.2014.11. 016.

37. Fantin F, Manica A, Soldani F, Bissoli L, Zivelonghi A, Zamboni M. Use of tigecycline in elderly patients for Clostridium difficile infection. Geriatr Gerontol Int. 2015;15:230-1. doi:10.1111/ggi.12336.

38. Herpers BL, Vlaminckx B, Burkhardt O, Blom $\mathrm{H}$, Biemond-Moeniralam HS, Hornef $M$, et al. Intravenous tigecycline as adjunctive or alternative therapy for severe refractory Clostridium difficile infection. Clin Infect Dis. 2009;48:1732-5. doi:10.1086/599224.

39. Larson KC, Belliveau PP, Spooner LM. Tigecycline for the treatment of severe Clostridium difficile infection. Ann Pharmacother. 2011;45:1005-10. doi:10.1345/aph.1Q080.

40. Navalkele BD, Lerner SA. Intravenous tigecycline facilitates cure of severe Clostridium difficile infection (CDI) after failure of standard therapy: a case report and literature review of tigecycline use in CDI. Open Forum Infect Dis 2016;3: ofw094. doi:10.1093/ofid/ofw094.

41. Tanaka SK, Steenbergen J, Villano S. Discovery, pharmacology, and clinical profile of omadacycline, a novel aminomethylcycline antibiotic. Bioorg Med Chem. 2016. doi:10.1016/j.bmc.2016.07.029.

42. Kim O, Leahy RG, Traczewsky M, Macone A, Steenbergen J, Tanaka SK. Activity and efficacy of Omadacycline against Clostridium difficile. Amsterdam: Eur Congr Clin Microbiol Infect Dis; 2016. 
43. Nakamura S, Nakashio S, Mikawa M, Yamakawa K, Okumura S, Nishida S. Antimicrobial susceptibility of Clostridium difficile from different sources. Microbiol Immunol. 1982;26:25-30.

44. Wenisch C, Parschalk B, Hasenhündl M, Hirschl AM, Graninger W. Comparison of vancomycin, teicoplanin, metronidazole, and fusidic acid for the treatment of Clostridium difficile-associated diarrhea. Clin Infect Dis. 1996;22:813-8. doi:10. 1093/clinids/22.5.813.

45. Wullt M, Odenholt I. A double-blind randomized controlled trial of fusidic acid and metronidazole for treatment of an initial episode of Clostridium difficile-associated diarrhoea. J Antimicrob Chemother. 2004;54:211-6. doi:10.1093/jac/ dkh278.

46. Norén T, Wullt M, Åkerlund T, Bäck E, Odenholt I, Burman LG. Frequent emergence of resistance in Clostridium difficile during treatment of $\mathrm{C}$. difficile-associated diarrhea with fusidic acid. Antimicrob Agents Chemother. 2006;50:3028-32. doi:10.1128/AAC.00019-06.

47. Citron DM, Tyrrell KL, Merriam CV, Goldstein EJC. Comparative in vitro activities of LFF571 against Clostridium difficile and 630 other intestinal strains of aerobic and anaerobic bacteria. Antimicrob Agents Chemother. 2012;56:2493-503. doi:10. 1128/AAC.06305-11.

48. Sachdeva M, Leeds JA. Subinhibitory concentrations of LFF571 reduce toxin production by clostridium difficile. Antimicrob Agents Chemother. 2015;59:1252-7. doi:10.1128/AAC.04436-14.

49. Leeds JA, Sachdeva M, Mullin S, Barnes SW, Ruzin A. In vitro selection, via serial passage, of Clostridium difficile mutants with reduced susceptibility to fidaxomicin or vancomycin. J Antimicrob Chemother. 2014;69:41-4. doi:10.1093/jac/dkt302.

50. Trzasko A, Leeds JA, Praestgaard J, LaMarche MJ, McKenney D. Efficacy of LFF571 in a hamster model of Clostridium difficile infection. Antimicrob Agents Chemother. 2012;56:4459-62. doi:10.1128/AAC. 06355-11.

51. Mullane K, Lee C, Bressler A, Buitrago M, Weiss K, Dabovic K, et al. Multicenter, randomized clinical trial to compare the safety and efficacy of LFF571 and vancomycin for Clostridium difficile infections. Antimicrob Agents Chemother. 2015;59:1435-40. doi:10.1128/AAC.04251-14.

52. Citron DM, Warren YA, Tyrrell KL, Merriam V, Goldstein EJC. Comparative in vitro activity of REP3123 against Clostridium difficile and other anaerobic intestinal bacteria. J Antimicrob
Chemother. 2009;63:972-6. doi:10.1093/jac/ dkp037.

53. Critchley IA, Green LS, Young CL, Bullard JM, Evans RJ, Price M, et al. Spectrum of activity and mode of action of REP3123, a new antibiotic to treat Clostridium difficile infections. J Antimicrob Chemother. 2009;63:954-63. doi:10.1093/jac/ dkp041.

54. Ochsner UA, Bell SJ, O'Leary AL, Hoang T, Stone $\mathrm{KC}$, Young CL, et al. Inhibitory effect of REP3123 on toxin and spore formation in Clostridium difficile, and in vivo efficacy in a hamster gastrointestinal infection model. J Antimicrob Chemother. 2009;63:964-71. doi:10.1093/jac/dkp042.

55. Clinical stage program targeting Clostridium difficile Infection, a devastating GI-tract infection with suboptimal therapies http://www.crestonepharma. com/index.php/cdi. Accessed 23 Sep 2016.

56. Mathur T, Kumar M, Barman TK, Kumar GR, Kalia V, Singhal S, et al. Activity of RBx 11760, a novel biaryl oxazolidinone, against Clostridium difficile. J Antimicrob Chemother. 2011;66:1087-95. doi:10. 1093/jac/dkr033.

57. Kumar M, Mathur T, Barman TK, Ramkumar G, Bhati A, Shukla G, et al. In Vitro and In Vivo activities of the novel ketolide RBx 14255 against Clostridium difficile. Antimicrob Agents Chemother. 2012;56:5986-9. doi:10.1128/AAC.00015-12.

58. Sully EK, Geller BL. Antisense antimicrobial therapeutics. Curr Opin Microbiol. 2016;33:47-55. doi:10.1016/j.mib.2016.05.017.

59. Hegarty JP, Krzeminski J, Sharma AK, Guzman-villanueva D, Weissig V, Sr. DBS. Bolaamphiphile-based nanocomplex delivery of phosphorothioate gapmer antisense oligonucleotides as a treatment for Clostridium difficile. Int J Nanomedicine. 2016;11:3607-19.

60. Dubreuil L, Houcke I, Mouton Y, Rossignol JF. In vitro evaluation of activities of nitazoxanide and tizoxanide against anaerobes and aerobic organisms. Antimicrob Agents Chemother. 1996;40:2266-70.

61. Rossignol JF. Nitazoxanide: a first-in-class broad-spectrum antiviral agent. Antiviral Res. 2014;110:94-103. doi:10.1016/j.antiviral.2014.07. 014.

62. Freeman J, Baines SD, Todhunter SL, Huscroft GS, Wilcox MH. Nitazoxanide is active against Clostridium difficile strains with reduced susceptibility to metronidazole. J Antimicrob Chemother. 2011;66:1407-8. doi:10.1093/jac/ dkr077. 
63. McVay CS, Rolfe RD. In vitro and in vivo activities of nitazoxanide against Clostridium difficile. Antimicrob Agents Chemother. 2000;44:2254-8. doi:10.1128/AAC.44.9.2254-2258.2000.

64. Musher DM, Logan N, Hamill RJ, Dupont HL, Lentnek A, Gupta A, et al. Nitazoxanide for the treatment of Clostridium difficile colitis. Clin Infect Dis. 2006;43:421-7. doi:10.1086/506351.

65. Musher DM, Logan N, Bressler AM, Johnson DP, Rossignol JF. Nitazoxanide versus vancomycin in Clostridium difficile infection: a randomized, double-blind study. Clin Infect Dis. 2009;48:e41-6. doi:10.1086/596552.

66. Pipeline and Publications. http://www.romark.com/ research/products-in-development. Accessed 14 Nov 2016.

67. Warren CA, Van Opstal E, Ballard TE, Kennedy A, Wang X, Riggins $M$, et al. Amixicile, a novel inhibitor of pyruvate: ferredoxin oxidoreductase, shows efficacy against Clostridium difficile in a mouse infection model. Antimicrob Agents Chemother. 2012;56:4103-11. doi:10.1128/AAC. 00360-12.

68. Hoffman PS, Bruce AM, Olekhnovich I, Warren CA, Burgess SL, Hontecillas R, et al. Preclinical studies of amixicile, a systemic therapeutic developed for treatment of Clostridium difficile infections that also shows efficacy against Helicobacter pylori. Antimicrob Agents Chemother. 2014;58:4703-12. doi:10.1128/AAC.03112-14.

69. Popovic N, Korac M, Nesic Z, Milosevic B, Urosevic A, Jevtovic D, et al. Oral teicoplanin for successful treatment of severe refractory Clostridium difficile infection. J Infect Dev Ctries. 2015;9:1062-7. doi:10.3855/jidc. 6335 .

70. Pantosti A, Luzzi IDA, Cardines R, Gianfrilli P. Comparison of the In vitro activities of teicoplanin and vancomycin against Clostridium difficile and their interactions with cholestyramine. Antimicrob Agents Chemother. 1985;28:847-8.

71. Wongwanich S, Kusum M, Phan-Urai R. Antibacterial activity of teicoplanin against Clostridium difficile. Southeast Asian J Trop Med Public Health. 1996;27:606-9.

72. de Lalla F, Privitera G, Rinaldi E, Ortisi G, Santoro D, Rizzardini G. Treatment of Clostridium difficile-associated disease with teicoplanin. Antimicrob Agents Chemother. 1989;33:1125-7.

73. de Lalla F, Nicolin R, Rinaldi E, Scarpellini P, Rigoli $\mathrm{R}$, Manfrin V, et al. Prospective study of oral teicoplanin versus oral vancomycin for therapy of pseudomembranous colitis and Clostridium difficile-associated diarrhea. Antimicrob Agents Chemother. 1992;36:2192-6. doi:10.1128/AAC.36. 10.2192 .

74. Nelson R, Kelsey P, Leeman H, Meardon N, Patel H, Paul K, et al. Antibiotic treatment for Clostridium difficile-associated diarrhea in adults (Review). Cochrane Database Syst Rev 2011;7:CD004610.

75. Biavasco F, Manso E, Varaldo PE. In vitro activities of ramoplanin and four glycopeptide antibiotics against clinical isolates of Clostridium difficile. Antimicrob Agents Chemother. 1991;35:195-7. doi:10.1128/AAC.35.1.195.

76. Peláez T, Alcallá L, Alonso R, Martín-López A, García-Arias V, Marín M, et al. In vitro activity of ramoplanin against Clostridium difficile, including strains with reduced susceptibility to vancomycin or with resistance to metronidazole. Antimicrob Agents Chemother. 2005;49:1157-9. doi:10.1128/ AAC.49.3.1157-1159.2005.

77. Freeman J, Baines SD, Jabes D, Wilcox MH. Comparison of the efficacy of ramoplanin and vancomycin in both in vitro and in vivo models of clindamycin-induced Clostridium difficile infection. J Antimicrob Chemother. 2005;56:717-25. doi:10.1093/jac/dki321.

78. Kraus CN, Lyerly MW, Carman RJ. Ambush of Clostridium difficile spores by Ramoplanin: activity in an in vitro model. Antimicrob Agents Chemother. 2015;59:2525-30. doi:10.1128/AAC.04853-14.

79. Pullman J, Prieto J, Leach T. Ramoplanin vs vancomycin in the treatment of Clostridium difficile diarrhea: A phase II study. 44th Intersci Conf Antimicrob Agents Chemother, Washington, D.C.: 2014.

80. NTI-851 (Ramoplanin ${ }^{\mathrm{TM}}$ ) http://www. nanotherapeutics.com/ramoplanin/. Accessed 27 Sep 2016.

81. O'Connor R, Baines SD, Freeman J, Wilcox $\mathrm{MH}$. In vitro susceptibility of genotypically distinct and clonal Clostridium difficile strains to oritavancin. J Antimicrob Chemother. 2008;62:762-5. doi:10. 1093/jac/dkn276.

82. Baines SD, O'Connor R, Saxton K, Freeman J, Wilcox MH. Comparison of oritavancin versus vancomycin as treatments for clindamycin-induced Clostridium difficile PCR ribotype 027 infection in a human gut model. J Antimicrob Chemother. 2008;62:1078-85. doi:10. 1093/jac/dkn358.

83. Chilton $\mathrm{CH}$, Freeman J, Crowther GS, Todhunter SL, Wilcox MH. Effectiveness of a short (4 day) course of oritavancin in the treatment of simulated 
Clostridium difficile infection using a human gut model. J Antimicrob Chemother. 2012;67:2434-7. doi:10.1093/jac/dks243.

84. Freeman J, Marquis M, Crowther GS, Todhunter SL, Fawley WN, Chilton $\mathrm{CH}$, et al. Oritavancin does not induce Clostridium difficile germination and toxin production in hamsters or a human gut model. J Antimicrob Chemother. 2012;67:2919-26. doi:10. 1093/jac/dks309.

85. Chilton $\mathrm{CH}$, Freeman J, Baines SD, Crowther GS, Nicholson S, Wilcox MH. Evaluation of the effect of oritavancin on Clostridium difficile spore germination, outgrowth and recovery. J Antimicrob Chemother. 2013;68:2078-82. doi:10.1093/jac/dkt160.

86. Yan H, Qi D, Cheng X, Song Z, Li W, He B. Antibiotic activities and affinities for bacterial cell wall analogue of $\mathrm{N}$-demethylvancomycin and its derivatives. J Antibiot (Tokyo). 1998;51:750-6.

87. Zhang SJ, Yang Q, Xu L, Chang J, Sun X. Synthesis and antibacterial activity against Clostridium difficile of novel demethylvancomycin derivatives. Bioorganic Med Chem Lett. 2012;22:4942-5. doi:10.1016/j.bmcl.2012.06.039.

88. Mathur H, O'Connor PM, Hill C, Cotter PD, Ross RP. Analysis of anti-Clostridium difficile activity of thuricin CD, vancomycin, metronidazole, ramoplanin, and actagardine, both singly and in paired combinations. Antimicrob Agents Chemother. 2013;57:2882-6. doi:10.1128/AAC. 00261-13.

89. Boakes S, Ayala T, Herman M, Appleyard AN, Dawson MJ, Cortés J. Generation of an actagardine A variant library through saturation mutagenesis. Appl Microbiol Biotechnol. 2012;95:1509-17. doi:10.1007/s00253-012-4041-0.

90. Crowther GS, Baines SD, Todhunter SL, Freeman J, Chilton $\mathrm{CH}$, Wilcox MH. Evaluation of NVB302 versus vancomycin activity in an in vitro human gut model of Clostridium difficile infection. J Antimicrob Chemother. 2013;68:168-76. doi:10. 1093/jac/dks359.

91. Assessment of the safety and distribution of NVB302 in healthy volunteers. http://www.isrctn. com/ISRCTN40071144. Accessed 27 Sep 2016.

92. Moore JH, van Opstal E, Kolling GL, Shin JH, Bogatcheva E, Nikonenko B, et al. Treatment of Clostridium difficile infection using SQ641, a capuramycin analogue, increases post-treatment survival and improves clinical measures of disease in a murine model. $\mathrm{J}$ Antimicrob Chemother. 2016;71:1300-6. doi:10.1007/s13398014-0173-7.2.
93. Alam MZ, Wu X, Mascio C, Chesnel L, Hurdle JG. Mode of action and bactericidal properties of surotomycin against growing and nongrowing clostridium difficile. Antimicrob Agents Chemother. 2015;59:5165-70. doi:10.1128/AAC. 01087-15.

94. Snydman DR, Jacobus NV, McDermott LA. Activity of a novel cyclic lipopeptide, CB-183,315, against resistant Clostridium difficile and other gram-positive aerobic and anaerobic intestinal pathogens. Antimicrob Agents Chemother. 2012;56:3448-52. doi:10.1128/AAC.06257-11.

95. Citron DM, Tyrrell KL, Merriam CV, Goldstein EJC. In vitro activities of CB-183,315, vancomycin, and metronidazole against 556 strains of Clostridium difficile, 445 other intestinal anaerobes, and 56 Enterobacteriaceae species. Antimicrob Agents Chemother. 2012;56:1613-5. doi:10.1128/AAC. 05655-11.

96. Citron DM, Tyrrell KL, Dale SE, Chesnel L, Goldstein EJC. Impact of Surotomycin on the Gut Microbiota of healthy volunteers in a phase 1 Clinical Trial. Antimicrob Agents Chemother 2016;2382: AAC.02531-15. doi:10.1128/AAC.02531-15.

97. Deshpande A, Hurless K, Cadnum JL, Chesnel L, Gao L, Chan L, et al. Effect of surotomycin, a novel cyclic lipopepide antibiotic, on intestinal colonization with vancomycin-resistant enterococci and Klebsiella pneumoniae in mice. Antimicrob Agents Chemother. 2016;60:3333-9. doi:10.1128/AAC.02904-15.

98. Mascio CTM, Chesnel L, Thorne G, Silverman JA. Surotomycin demonstrates low in vitro frequency of resistance and rapid bactericidal activity in Clostridium difficile, Enterococcus faecalis, and Enterococcus faecium. Antimicrob Agents Chemother. 2014;58:3976-82. doi:10.1128/AAC. 00124-14.

99. Adams HM, Li X, Mascio C, Chesnel L, Palmer KL. Mutations associated with reduced surotomycin susceptibility in Clostridium difficile and Enterococcus species. Antimicrob Agents Chemother. 2015;59:4139-47. doi:10.1128/AAC. 00526-15.

100. Lee CH, Patino H, Stevens C, Rege S, Chesnel L, Louie $\mathrm{T}$, et al. Surotomycin versus vancomycin for Clostridium difficile infection: Phase 2, randomized, controlled, double-blind, non-inferiority, multicentre trial. J Antimicrob Chemother. 2016;71:2964-71. doi:10.1093/jac/dkw246.

101. Study of CB-183,315 in Patients With Clostridium difficile Associated Diarrhea. https://clinicaltrials. gov/ct $2 /$ results?term=surotomycin + phase $+3 \&$ Sear ch=Search. Accessed 27 Sep 2016. 
102. Boix V, Pesant Y, Fedorak R, Mullane K, Stoutenburgh U, Jin $\mathrm{M}$, et al. Primary clinical outcomes from a Phase 3, randomized, double-blind, active-controlled study of surotomycin in patients with Clostridium difficile associated diarrhea. Amsterdam: Eur Congr Clin Microbiol Infect Dis; 2016.

103. Merck Pipeline. http://www.merck.com/research/ pipeline/home.html. Accessed 13 Oct 2016.

104. Rea MC, Sit CS, Clayton E, O'Connor PM, Whittal $\mathrm{RM}$, Zheng $\mathrm{J}$, et al. Thuricin CD, a posttranslationally modified bacteriocin with a narrow spectrum of activity against Clostridium difficile. Proc Natl Acad Sci USA. 2010;107:9352-7. doi:10.1073/pnas.0913554107.

105. Rea MC, Dobson A, O'Sullivan O, Crispie F, Fouhy F, Cotter PD, et al. Effect of broad- and narrow-spectrum antimicrobials on Clostridium difficile and microbial diversity in a model of the distal colon. Proc Natl Acad Sci USA. 2011;108:4639-44. doi:10.1073/pnas.1001224107.

106. Mathur H, Rea MC, Cotter PD, Hill C, Ross RP. The efficacy of thuricin $\mathrm{CD}$, tigecycline, vancomycin, teicoplanin, rifampicin and nitazoxanide, independently and in paired combinations against Clostridium difficile biofilms and planktonic cells. Gut Pathog. 2016;8:20. doi:10.1186/s13099-0160102-8.

107. Sangster W, Hegarty JP, Stewart DB. Phage tail-like particles kill Clostridium difficile and represent an alternative to conventional antibiotics. Surg (United States). 2015;157:96-103. doi:10.1016/j. surg.2014.06.015.

108. Gebhart D, Lok S, Clare S, Tomas M, Stares M, Scholl $\mathrm{D}$, et al. A modified R-type bacteriocin specifically targeting Clostridium difficile prevents colonization of mice without affecting gut microbiota diversity. MBio. 2015;6:1-13. doi:10.1128/mBio.02368-14. Editor.

109. AvidBiotics, Bacterial Diseases. http://avidbiotics. com/technology/avidocin-proteins/bacterial-diseas es/. Accessed 29 Sep 2016.

110. Wang Q, Euler CW, Delaune A, Fischetti VA. Using a novel lysin to help control Clostridium difficile infections. Antimicrob Agents Chemother 2015;59:AAC.01357-15. doi:10.1128/AAC.0135715.

111. Locher HH, Caspers $P$, Bruyère $T$, Schroeder S, Pfaff $\mathrm{P}$, Knezevic A, et al. Investigations of the Mode of Action and Resistance Development of Cadazolid, a New Antibiotic for Treatment of Clostridium difficile Infections. Antimicrob Agents Chemother. 2014;58:901-8. doi:10.1128/AAC.01831-13.
112. Gerding DN, Hecht DW, Louie T, Nord CE, Talbot $\mathrm{GH}$, Cornely OA, et al. Susceptibility of Clostridium difficile isolates from a Phase 2 clinical trial of cadazolid and vancomycin in C. difficile infection. J Antimicrob Chemother 2015:dkv300. doi:10. 1093/jac/dkv300.

113. Chilton $\mathrm{CH}$, Crowther GS, Baines SD, Todhunter SL, Freeman J, Locher $\mathrm{HH}$, et al. In vitro activity of cadazolid against clinically relevant Clostridium difficile isolates and in an in vitro gut model of C. difficile infection. J Antimicrob Chemother. 2014;69:697-705. doi:10.1093/jac/dkt411.

114. Seiler P, Enderlin-Paput M, Pfaff P, Weiss M, Ritz D, Clozel $\mathrm{M}$, et al. Cadazolid does not promote intestinal colonization of vancomycin-resistant enterococci in mice. Antimicrob Agents Chemother. 2016;60:628-31. doi:10.1128/AAC. 01923-15.

115. Louie T, Nord CE, Talbot GH, Wilcox M, Gerding DN, Buitrago M, et al. A Multicenter, Double-blind, randomized, phase 2 study evaluating the novel antibiotic, cadazolid, in patients with Clostridium difficile infection. Antimicrob Agents Chemother 2015;59:AAC.00504-15. doi:10.1128/AAC.0050415.

116. ClinicalTrial.gov. https://clinicaltrials.gov/ct2/ results?term $=$ cadazolid\&recr=Open. Accessed 2 Oct 2016.

117. Rashid MU, Dalhoff A, Weintraub A, Nord CE. Invitro activity of MCB3681 against Clostridium difficile strains. Anaerobe. 2014;28:216-9. doi:10. 1016/j.anaerobe.2014.07.001.

118. Dalhoff A, Rashid M-U, Kapsner T, Panagiotidis G, Weintraub A, Nord CE. Analysis of effects of MCB3681, the antibacterially active substance of prodrug MCB3837, on human resident microflora as proof of principle. Clin Microbiol Infect 2015;21:767.e1-767.e4. doi:10.1016/j.cmi.2015.05. 025.

119. Morphochem. http://www.morphochem.de/. Accessed 29 Sep 2016.

120. Butler MM, LaMarr WA, Foster KA, Barnes MH, Skow DJ, Lyden PT, et al. Antibacterial activity and mechanism of action of a novel anilinouracil-fluoroquinolone hybrid compound. Antimicrob Agents Chemother. 2007;51:119-27. doi:10.1128/AAC.01311-05.

121. Butler MM, Shinabarger DL, Citron DM, Kelly CP, Dvoskin S, Wright GE, et al. MBX-500, a hybrid antibiotic with in vitro and in vivo efficacy against toxigenic Clostridium difficile. Antimicrob Agents Chemother. 2012;56:4786-92. doi:10.1128/AAC. 00508-12. 
122. Steele J, Zhang Q, Beamer G, Butler M, Bowlin T, Tzipori S. MBX-500 Is effective for treatment of Clostridium difficile infection in gnotobiotic piglets. Antimicrob Agents Chemother. 2013;57:4039-41. doi:10.1128/AAC.00304-13.

123. Iscla I, Wray R, Blount P, Larkins-ford J, Conery AL, Ausubel FM, et al. A new antibiotic with potent activity targets MscL. J Antibiot (Tokyo). 2015;68:1-10. doi:10.1038/ja.2015.4.

124. James E, Viola H, Hool L, Eggers PK, Raston CL, Boulos RA. A novel antimicrobial agent reduces oxidative stress in cells. RSC Adv. 2013;3:7277. doi:10.1039/c3ra40658j.

125. Rao S, Prestidge CA, Miesel L, Sweeney D, Shinabarger DL, Boulos RA. Preclinical development of Ramizol, an antibiotic belonging to a new class, for the treatment of Clostridium difficile colitis. J Antibiot (Tokyo). 2016;. doi:10. 1038/ja.2016.45.

126. Ramizol ${ }^{\circledR}$ : A new treatment for Clostridium difficile associated disease. http://bouloscooper.com/wpcontent/uploads/2014/10/Ramizol-A-new-treatmentfor-Clostridium-difficile-asociated-disease.pdf. Accessed 29 Sep 2016.

127. Salzman NH. Microbiota-immune system interaction: an uneasy alliance. Curr Opin Microbiol. 2011;14:99-105. doi:10.1016/j.mib. 2010.09.018.Microbiota-Immune.

128. Giesemann T, Guttenberg G, Aktories K. Human alpha-defensins inhibit Clostridium difficile toxin $\mathrm{B}$. Gastroenterology. 2008;134:2049-58. doi:10.1053/ j.gastro.2008.03.008.

129. Furci L, Baldan R, Bianchini V, Trovato A, Ossi C, Cichero $\mathrm{P}$, et al. New role for human alpha-defensin 5 in the fight against hypervirulent Clostridium difficile strains. Infect Immun. 2015;83:986-95. doi:10.1128/IAI.02955-14.

130. Shilling M, Matt L, Rubin E, Visitacion MP, Haller NA, Grey SF, et al. Antimicrobial effects of virgin coconut oil and its medium-chain fatty acids on Clostridium difficile. J Med Food. 2013;16:1079-85. doi:10.1089/jmf.2012.0303.

131. Kabara JJ, Swieczkowski DM, Conley AJ, Truant JP. Fatty acids and derivatives as antimicrobial agents. Antimicrob Agents Chemother. 1972;2:23-8. doi:10.1128/AAC.2.1.23.

132. Weiss W, Pulse M, Vickers R. In vivo assessment of SMT19969 in a hamster model of Clostridium difficile infection. Antimicrob Agents Chemother. 2014;58:5714-8. doi:10.1128/AAC.02903-14.
133. Freeman J, Vernon J, Vickers R, Wilcox $M H$. Susceptibility of Clostridium difficile isolates of varying antimicrobial resistance phenotypes to SMT19969 and 11 comparators. Antimicrob Agents Chemother. 2015;60:689-92. doi:10.1128/ AAC.02000-15.

134. Baines SD, Crowther GS, Freeman J, Todhunter S, Vickers R, Wilcox MH. SMT19969 as a treatment for Clostridium difficile infection: an assessment of antimicrobial activity using conventional susceptibility testing and an in vitro gut model. J Antimicrob Chemother. 2015;70:182-9. doi:10. 1093/jac/dku324.

135. Bassères E, Endres BT, Khaleduzzaman M, Miraftabi F, Alam MJ, Vickers RJ, et al. Impact on toxin production and cell morphology in Clostridium difficile by ridinilazole (SMT19969), a novel treatment for $C$. difficile infection. J Antimicrob Chemother. 2016;71:1245-51. doi:10.1093/jac/ dkv498.

136. Sattar A, Thommes P, Payne L, Warn P, Vickers RJ. SMT19969 for Clostridium difficile infection (CDI): in vivo efficacy compared with fidaxomicin and vancomycin in the hamster model of CDI. J Antimicrob Chemother. 2015;70:1757-62. doi:10.1093/jac/dkv005.

137. Vickers R, Tillotson G, Nathan R, Hazam S, Lucasti C, Pullman J, et al. Ridinilazole for Clostridium difficile infections: safety and efficacy compared with vancomycin from the CoDIFy Phase 2 Trial. Amsterdam: Eur Congr Clin Microbiol Infect Dis; 2016.

138. C. difficile Infection. http://www.summitplc.com/ programmes/c-difficile-infections/. Accessed 29 Sep 2016.

139. Lv Z, Peng G, Liu W, Xu H, Su J. Berberine blocks the relapse of Clostridium difficile infection in C57BL/6 mice after vancomycin standard treatment. Antimicrob Agents Chemother 2015;59:AAC.04794-14. doi:10.1128/AAC.04794-14.

140. Wang S, Setlow B, Setlow P, Li Y. Uptake and levels of the antibiotic berberine in individual dormant and germinating Clostridium difficile and Bacillus cereus spores as measured by laser tweezers Raman spectroscopy. J Antimicrob Chemother. 2016;71:1540-6. doi:10.1093/jac/dkv504.

141. Teraguchi S, Shin K, Ozawa K, Nakamura S, Fukuwatari Y, Tsuyuki S, et al. Bacteriostatic effect of orally administered bovine lactoferrin on proliferation of Clostridium species in the gut of mice fed bovine milk. Appl Environ Microbiol. 1995;61:501-6. 
142. Boone JH, Dipersio JR, Tan MJ, Salstrom SJ, Wickham KN, Carman RJ, et al. Elevated lactoferrin is associated with moderate to severe Clostridium difficile disease, stool toxin, and 027 infection. Eur J Clin Microbiol Infect Dis. 2013;32:1517-23. doi:10.1007/s10096-013-1905-X.

143. Chilton $\mathrm{CH}$, Crowther GS, Śpiewak K, Brindell M, Singh G, Wilcox $\mathrm{MH}$, et al. Potential of lactoferrin to prevent antibiotic-induced Clostridium difficile infection. $\mathrm{J}$ Antimicrob Chemother. 2016;71:975-85. doi:10.1093/jac/dkv452.

144. Bovine Lactoferrin and Antibiotic-associated Diarrhoea. (BLAAD). https://clinicaltrials.gov/ct2/ show/NCT02626104?term=lactoferrin+clostridium \&rank=3. Accessed 1 Oct 2016.

145. De Sordi L, Butt MA, Pye H, Kohoutova D, Mosse CA, Yahioglu $G$, et al. Development of photodynamic antimicrobial chemotherapy (PACT) for Clostridium difficile. PLoS One. 2015;10:1-17. doi:10.1371/journal.pone.0135039.

146. Taylor NS, Bartlett JG. Binding of Clostridium difficile cytotoxin and vancomycin by anion-exchange resins. J Infect Dis. 1980;141:92-7.

147. Kunimoto D, Thomson AB. Recurrent Clostridium difficile-associated colitis responding to cholestyramine. Digestion. 1986;33:225-8.

148. Moncino MD, Falletta JM. Multiple relapses of Clostridium difficile-associated diarrhea in a cancer patient. Successful control with long-term cholestyramine therapy. Am J Pediatr Hematol Oncol. 1992;14:361-4.

149. Puri BK, Hakkarainen-Smith JS, Monro JA. The potential use of cholestyramine to reduce the risk of developing Clostridium difficile-associated diarrhoea in patients receiving long-term intravenous ceftriaxone. Med Hypotheses. 2015;84:78-80. doi:10.1016/j.mehy.2014.11.020.

150. Kurtz CB, Cannon EP, Brezzani A, Pitruzzello M, Dinardo C, Rinard E, et al. GT160-246, a toxin binding polymer for treatment of Clostridium difficile colitis. Antimicrob Agents Chemother. 2001;45:2340-7. doi:10.1128/AAC.45.8.2340-2347. 2001.

151. Louie TJ, Peppe J, Watt CK, Johnson D, Mohammed $\mathrm{R}$, Dow $\mathrm{G}$, et al. Tolevamer, a novel nonantibiotic polymer, compared with vancomycin in the treatment of mild to moderately severe Clostridium difficile-associated diarrhea. Clin Infect Dis. 2006;43:411-20. doi:10.1086/506349.

152. Baines SD, Freeman J, Wilcox MH. Tolevamer is not efficacious in the neutralization of cytotoxin in a human gut model of Clostridium difficile infection.
Antimicrob Agents Chemother. 2009;53:2202-4. doi:10.1128/AAC.01085-08.

153. Johnson S, Louie TJ, Gerding DN, Cornely O a., Chasan-Taber S, Fitts D, et al. Vancomycin, metronidazole, or tolevamer for Clostridium difficile infection: results from two multinational, randomized, controlled trials. Clin Infect Dis 2014;59:345-54. doi:10.1093/cid/ciu313.

154. Weiss K. Toxin-binding treatment for Clostridium difficile: a review including reports of studies with tolevamer. Int J Antimicrob Agents. 2009;33:4-7. doi:10.1016/j.ijantimicag.2008.07.011.

155. Dadu R, Hu MI, Cleeland C, Busaidy NL, Habra M, Waguespack SG, et al. Efficacy of the natural clay, calcium aluminosilicate anti-diarrheal, in reducing medullary thyroid cancer-related diarrhea and its effects on quality of life: a pilot study. Thyroid. 2015;25:1085-90. doi:10.1089/ thy.2015.0166.

156. Kee BK, Morris JS, Slack RS, Crocenzi T, Wong L, Esparaz B, et al. A phase II, randomized, double blind trial of calcium aluminosilicate clay versus placebo for the prevention of diarrhea in patients with metastatic colorectal cancer treated with irinotecan. Support Care Cancer. 2015;23:661-70. doi:10.1007/s00520-014-2402-1.

157. Sturino JM, Pokusaeva K, Carpenter R. Effective sequestration of Clostridium difficile protein toxins by calcium aluminosilicate. Antimicrob Agents Chemother. 2015;59:7178-83. doi:10.1128/AAC. 05050-14.

158. Proof-of-Concept, Calcium Aluminosilicate Anti-Diarrheal (CASAD) for Treatment of Clostridium difficile Infection. https://clinicaltrials. gov/ct2/show/NCT01570634?term=casad\&rank=2. Accessed 29 Sep 2016.

159. Ivarsson ME, Durantie E, Hueberli C, Huwiler S, Lu J, Verdu EF, et al. Therapeutic potential of small molecule triggers of pre-emptive Clostridium difficile Toxin B auto-proteolysis. 5th Int Clostridium difficile Symp, Bled, Slovenia: 2015.

160. Inositec AG. http://inositec.com/. Accessed 17 Oct 2016.

161. Lyerly DM, Bostwick EF, Binion SB, Wilkins TD. Passive immunization of hamsters against disease caused by clostridium dijficile by use of bovine immunoglobulin $G$ concentrate. Immunology. 1991;59:2215-8.

162. Kelly CP, Pothoulakis C, Vavva F, Castagliuolo I, Bostwick EF, Keane JCO, et al. Anti- Clostridium difficile bovine immunoglobulin concentrate inhibits cytotoxicity and enterotoxicity of $C$. 
difficile toxins. Antimicrob Agents Chemother. 1996;40:373-9.

163. Sponseller JK, Steele JA, Schmidt DJ, Kim HB, Beamer G, Sun $X$, et al. Hyperimmune bovine colostrum as a novel therapy to combat Clostridium difficile infection. J Infect Dis. 2015;211:1334-41. doi:10.1093/infdis/jiu605.

164. Young KWH, Munro IC, Taylor SL, Veldkamp P, van Dissel JT. The safety of whey protein concentrate derived from the milk of cows immunized against Clostridium difficile. Regul Toxicol Pharmacol. 2007;47:317-26. doi:10.1016/ j.yrtph.2006.12.001.

165. Mattila E, Anttila V-J, Broas M, Marttila H, Poukka $\mathrm{P}$, Kuusisto $\mathrm{K}$, et al. A randomized, double-blind study comparing Clostridium difficile immune whey and metronidazole for recurrent Clostridium difficile-associated diarrhoea: efficacy and safety data of a prematurely interrupted trial. Scand J Infect Dis. 2008;40:702-8. doi:10.1080/ 00365540801964960 .

166. Abougergi MS, Kwon JH. Intravenous immunoglobulin for the treatment of Clostridium difficile infection: a review. Dig Dis Sci. 2011;56:19-26. doi:10.1007/s10620-010-1411-2.

167. IVIG Versus Placebo for the Treatment of Patients With Severe C-Diff. https://clinicaltrials.gov/ct2/ show/NCT00177970?term=ivig+clostridium\&rank =1. Accessed 30 Sep 2016 .

168. Juang P, Skledar SJ, Zgheib NK, Paterson DL, Vergis EN, Shannon WD, et al. Clinical outcomes of intravenous immune globulin in severe clostridium difficile-associated diarrhea. Am J Infect Control. 2007;35:131-7. doi:10.1016/j.ajic. 2006.06.007.

169. Shahani L, Koirala J. Use of intravenous immunoglobulin in severe Clostridium difficile -associated diarrhea. Hosp Pract. 2015;43:154-7. doi:10.1080/21548331.2015.1071636.

170. Babcock GJ, Broering TJ, Hernandez HJ, Mandell RB, Donahue K, Boatright N, et al. Human monoclonal antibodies directed against toxins $\mathrm{A}$ and $\mathrm{B}$ prevent Clostridium difficile-induced mortality in hamsters. Infect Immun. 2006;74:6339-47. doi:10.1128/IAI. 00982-06.

171. Lowy I, Molrine D, Leav BA, Blair B, Baxter R, Gerding DN, et al. Treatment with monoclonal antibodies against Clostridium difficile toxins Israel. N Engl J Med. 2010;362:197-205. doi:10.1056/ NEJMoa1201637.

172. Gerding DN, Kelly C, Rahav G, Lee C, Dubberke E, Kumar P, et al. Efficacy of Bezlotoxumab, the
Monoclonal Antibody Targeting C. difficile Toxin $\mathrm{B}$, for Prevention of C. difficile Infection (CDI) Recurrence in Patients at High Risk of Recurrence or CDI-Related Adverse Outomes. Eur Congr Clin Microbiol Infect Dis, Amsterdam: 2016.

173. FDA Approves Merck's ZINPLAVA ${ }^{\mathrm{TM}}$ (bezlotoxumab) to Reduce Recurrence of Clostridium difficile Infection (CDI) in Adult Patients Receiving Antibacterial Drug Treatment for CDI Who Are at High Risk of CDI Recurrence. http://www.mercknewsroom.com/ news-release/corporate-news/fda-approves-merckszinplava-bezlotoxumab-reduce-recurrence-clostri dium. Accessed 14 Nov 2016.

174. Roberts A, Mcglashan J, Ibrahim AA, Ling R, Denton $\mathrm{H}$, Green S, et al. Development and evaluation of an ovine antibody-based platform for treatment of Clostridium difficile infection. Infect Immun. 2012;80:875-82. doi:10.1128/IAI.05684-11.

175. Product Pipeline. http://micropharm.co.uk/ products/product_pipeline/. Accessed 30 Sep 2016.

176. Davies NL, Compson JE, MacKenzie B, O’Dowd VL, Oxbrow AKF, Heads JT, et al. A mixture of functionally oligoclonal humanized monoclonal antibodies that neutralize Clostridium difficile tcda and tcdb with high levels of in vitro potency shows in vivo protection in a hamster infection model. Clin Vaccine Immunol. 2013;20:377-90. doi:10. 1128/CVI.00625-12.

177. Qiu H, Cassan R, Johnstone D, Han X, Joyee AG, McQuoid M, et al. Novel Clostridium difficile Anti-Toxin (TcdA and TcdB) humanized monoclonal antibodies demonstrate in vitro neutralization across a broad spectrum of clinical strains and in vivo potency in a hamster spore challenge model. PLoS One. 2016;11:e0157970. doi:10.1371/journal.pone.0157970.

178. Anosova NG, Cole LE, Li L, Zhang J, Brown AM, Mundle S, et al. A combination of three fully human toxin A- and toxin B-specific monoclonal antibodies protects against challenge with highly virulent epidemic strains of Clostridium difficile in the hamster model. Clin Vaccine Immunol. 2015;22:711-25. doi:10.1128/CVI.00763-14.

179. Yang Z, Schmidt D, Liu W, Li S, Shi L, Sheng J, et al. A novel multivalent, single-domain antibody targeting TcdA and TcdB prevents fulminant Clostridium difficile infection in mice. J Infect Dis. 2014;210:964-72. doi:10.1093/infdis/jiu196.

180. Schmidt DJ, Beamer G, Tremblay JM, Steele JA, Kim $\mathrm{HB}$, Wang $\mathrm{Y}$, et al. A tetraspecific VHH-based neutralizing antibody modifies disease outcome in three animal models of Clostridium difficile infection. Clin Vaccine Immunol. 2016;23:774-84. doi:10.1128/CVI.00730-15. 
181. Hussack G, Tanha J. An update on antibody-based immunotherapies for Clostridium difficile infection. Clin Exp Gastroenterol. 2016;9:209-24. doi:10. 2147/CEG.S84017.

182. Anosova NG, Brown AM, Li L, Liu N, Cole LE, Zhang $\mathrm{J}$, et al. Systemic antibody responses induced by a two-component Clostridium difficile toxoid vaccine protect against $C$. difficile-associated disease in hamsters. J Med Microbiol. 2013;62:1394-404. doi:10.1099/jmm.0.056796-0.

183. Greenberg RN, Marbury TC, Foglia G, Warny M. Phase I dose finding studies of an adjuvanted Clostridium difficile toxoid vaccine. Vaccine. 2012;30:2245-9. doi:10.1016/j.vaccine.2012.01.065.

184. de Bruyn G, Saleh J, Workman D, Pollak R, Elinoff $\mathrm{V}$, Fraser NJ, et al. Defining the optimal formulation and schedule of a candidate toxoid vaccine against Clostridium difficile infection: a randomized Phase 2 clinical trial. Vaccine. 2016;34:2170-8. doi:10.1016/ j.vaccine.2016.03.028.

185. Study of a Candidate Clostridium difficile Toxoid Vaccine (Cdiffense) in Subjects at Risk for C. Difficile infection. https://clinicaltrials.gov/ct2/ show/NCT01887912?term=cdiffense\&rank=1. Accessed 29 Sep 2016.

186. Sheldon E, Kitchin N, Peng Y, Eiden J, Gruber W, Johnson E, et al. A phase 1, placebo-controlled, randomized study of the safety, tolerability, and immunogenicity of a Clostridium difficile vaccine administered with or without aluminum hydroxide in healthy adults. Vaccine. 2016;34:2082-91. doi:10.1016/j.vaccine.2016.03.010.

187. ClinicalTrials.gov. https://clinicaltrials.gov/ct2/ results?term=pfizer+clostridium $+\% 22$ phase $+2 \% 22$ $\&$ Search=Search. Accessed 30 Sep 2016.

188. Bézay N, Ayad A, Dubischar K, Firbas C, Hochreiter $\mathrm{R}$, Kiermayr $\mathrm{S}$, et al. Safety, immunogenicity and dose response of VLA84, a new vaccine candidate against Clostridium difficile, in healthy volunteers. Vaccine. 2016;34:2585-92. doi:10.1016/j.vaccine. 2016.03.098.

189. Valneva's Clostridium difficile vaccine candidateVLA84. http://www.valneva.com/en/rd/vla84. Accessed 29 Sep 2016.

190. Gardiner DF, Rosenberg T, Zaharatos J, Franco D, Ho DD. A DNA vaccine targeting the receptor-binding domain of Clostridium difficile toxin A. Vaccine. 2009;27:3598-604. doi:10.1126/ scisignal.2001449.Engineering.

191. Jin K, Wang S, Zhang C, Xiao Y, Lu S, Huang Z. Protective antibody responses against Clostridium difficile elicited by a DNA vaccine expressing the enzymatic domain of toxin B. Hum Vaccines Immunother. 2013;9:63-73. doi:10.4161/hv.22434.

192. Baliban SM, Michael A, Shammassian B, Mudakha S, Khan AS, Cocklin S, et al. An optimized, synthetic DNA vaccine encoding the toxin $A$ and toxin $B$ receptor binding domains of Clostridium difficile induces protective antibody responses in vivo. Infect Immun. 2014;82:4080-91. doi:10.1128/IAI. 01950-14.

193. Ní Eidhin DB, O’Brien JB, McCabe MS, Athié-Morales V, Kelleher DP. Active immunization of hamsters against Clostridium difficile infection using surface-layer protein. FEMS Immunol Med Microbiol. 2008;52:207-18. doi:10. 1111/j.1574-695X.2007.00363.X.

194. Bruxelle J-F, Mizrahi A, Hoys S, Collignon A, Janoir C, Péchiné S. Immunogenic properties of the surface layer precursor of Clostridium difficile and vaccination assays in animal models. Anaerobe. 2015;37:78-84. doi:10.1016/j.anaerobe.2015.10. 010 .

195. Péchiné S, Denève C, Le Monnier A, Hoys S, Janoir C, Collignon A. Immunization of hamsters against Clostridium difficile infection using the Cwp84 protease as an antigen. FEMS Immunol Med Microbiol. 2011;63:73-81. doi:10.1111/j.1574695X.2011.00832.x.

196. Sandolo C, Péchiné S, Le Monnier A, Hoys S, Janoir C, Coviello T, et al. Encapsulation of Cwp84 into pectin beads for oral vaccination against Clostridium difficile. Eur J Pharm Biopharm. 2011;79:566-73. doi:10.1016/j.ejpb.2011.05.011.

197. Péchiné S, Janoir C, Boureau H, Gleizes A, Tsapis N, Hoys S, et al. Diminished intestinal colonization by Clostridium difficile and immune response in mice after mucosal immunization with surface proteins of Clostridium difficile. Vaccine. 2007;25:3946-54. doi:10.1016/j.vaccine.2007.02.055.

198. Ghose C, Eugenis I, Sun X, Edwards AN, McBride $\mathrm{SM}$, Pride DT, et al. Immunogenicity and protective efficacy of recombinant Clostridium difficile flagellar protein FliC. Emerg Microbes Infect. 2016;5:e8. doi:10.1016/j.anaerobe.2015.12.001.

199. Bertolo L, Boncheff AG, Ma Z, Chen YH, Wakeford $\mathrm{T}$, Friendship $\mathrm{RM}$, et al. Clostridium difficile carbohydrates: glucan in spores, PSII common antigen in cells, immunogenicity of PSII in swine and synthesis of a dual $C$. difficile-ETEC conjugate vaccine. Carbohydr Res. 2012;354:79-85. doi:10. 1016/j.carres.2012.03.032.

200. Martin CE, Broecker F, Oberli MA, Komor J, Mattner $\mathrm{J}$, Anish C, et al. Immunological evaluation of a synthetic Clostridium difficile oligosaccharide 
conjugate vaccine candidate and identification of a minimal epitope. J Am Chem Soc. 2013;135:9713-22. doi:10.1021/ja401410y.

201. Oberli MA, Hecht ML, Bindschädler P, Adibekian A, Adam T, Seeberger PH. A possible oligosaccharide-conjugate vaccine candidate for Clostridium difficile is antigenic and immunogenic. Chem Biol. 2011;18:580-8. doi:10.1016/j.chembiol. 2011.03.009.

202. Broecker F, Martin CE, Wegner E, Mattner J, Baek JY, Pereira CL, et al. Synthetic lipoteichoic acid glycans are potential vaccine candidates to protect from Clostridium difficile infections. Cell Chem Biol. 2016;23:1014-22. doi:10.1016/j.chembiol.2016.07. 009 .

203. Spencer J, Leuzzi R, Buckley A, Irvine J, Candlish D, Scarselli $\mathrm{M}$, et al. Vaccination against Clostridium difficile using toxin fragments. Gut Microbes. 2014;5:225-32.

204. Leuzzi R, Adamo R, Scarselli M. Vaccines against clostridium difficile. Hum Vaccines Immunother. 2014;10:1466-77.

205. Seekatz AM, Rao K, Santhosh K, Young VB. Dynamics of the fecal microbiome in patients with recurrent and nonrecurrent Clostridium difficile infection. Genome Med. 2016;8:47. doi:10. 1186/s13073-016-0298-8.

206. Kelly CR, Khoruts A, Staley C, Sadowsky MJ, Abd M, Alani $M$, et al. Effect of fecal microbiota transplantation on recurrence in multiply recurrent Clostridium difficile infection: a randomized trial. Ann Intern Med. 2016;. doi:10. 7326/M16-0271.

207. Cammarota G, Masucci L, Ianiro G, Bibbò S, Dinoi G, Costamagna $G$, et al. Randomised clinical trial: faecal microbiota transplantation by colonoscopy vs. vancomycin for the treatment of recurrent Clostridium difficile infection. Aliment Pharmacol Ther. 2015;41:835-43. doi:10.1111/ apt.13144.

208. Stool Transplant in Pediatric Patients With Recurring C. Difficile Infection. https:// clinicaltrials.gov/ct2/show/NCT01972334?term=N CT01972334\&rank=1. Accessed 29 Sep 2016.

209. ClinicalTrials.gov. https://clinicaltrials.gov/ct2/ results?term=stool+transplant + clostridium\&recr $=$ Open. Accessed 1 Oct 2016.

210. Youngster I, Sauk J, Pindar C, Wilson RG, Kaplan JL, Smith $\mathrm{MB}$, et al. Fecal microbiota transplant for relapsing Clostridium difficile infection using a frozen inoculum from unrelated donors: a randomized, open-label, controlled pilot study.
Clin Infect Dis. 2014;58:1515-22. doi:10.1093/cid/ ciu135.

211. Lee CH, Steiner T, Petrof EO, Smieja M, Roscoe D, Nematallah A, et al. Frozen vs fresh fecal microbiota transplantation and clinical resolution of diarrhea in patients with recurrent Clostridium difficile infection. JAMA. 2016;315:142. doi:10.1001/jama. 2015.18098.

212. Zipursky JS, Sidorsky TI, Freedman CA, Sidorsky $\mathrm{MN}$, Kirkland KB. Patient attitudes toward the use of fecal microbiota transplantation in the treatment of recurrent Clostridium difficile infection. Clin Infect Dis. 2012;55:1652-8. doi:10.1093/cid/cis809.

213. Zipursky JS, Sidorsky TI, Freedman CA, Sidorsky $\mathrm{MN}$, Kirkland KB. Physician attitudes toward the use of fecal microbiota transplantation for the treatment of recurrent Clostridium difficile infection. Clin Infect Dis. 2014;28:319-24. doi:10. 1093/cid/cis809.

214. Moossavi S, Salimzadeh H, Katoonizadeh A, Mojarrad A, Merat D, Ansari R, et al. Physicians' knowledge and attitude towards fecal microbiota transplant in Iran. Middle East J Dig Dis. 2015;7:155-60.

215. Youngster I, Russell GH, Pindar C, Ziv-Baran T, Sauk J, Hohmann EL. Oral, Capsulized, frozen fecal microbiota transplantation for relapsing Clostridium difficile infection. JAMA. 2014;312:1772-8. doi:10.1001/jama.2014.13875.

216. Tian H, Ding C, Gong J, Wei Y, McFarland LV, Li N. Freeze-dried, capsulized fecal microbiota transplantation for relapsing Clostridium difficile infection. J Clin Gastroenterol. 2015;49:537-8.

217. Hecker MT, Obrenovich ME, Cadnum JL, Jenson A, Jain AK, Ho E, et al. Fecal microbiota transplantation by freeze-dried oral capsules for reurrent Clostridium diffiicile infection. Open Forum Infect Dis. 2016;3:1-2. doi:10.1093/ofid/ofw091.

218. Orenstein R, Dubberke E, Hardi R, Ray A, Mullane K, Pardi DS, et al. Safety and durability of RBX2660 (microbiota suspension) for recurrent Clostridium difficile infection: results of the PUNCH CD study. Clin Infect Dis. 2015;2660:1-6. doi:10.1093/cid/ civ938.

219. RBX2660 Clinical Trials. http://www.rebiotix.com/ clinical-trials/rbx2660-clinical-trials/. Accessed 1 Oct 2016.

220. Khanna S, Pardi DS, Kelly CR, Kraft CS, Dhere T, Henn MR, et al. A novel microbiome therapeutic increases gut microbial diversity and prevents recurrent Clostridium difficile infection. J Infect Dis. 2016;214:173-81. doi:10.1093/infdis/jiv766. 
221. SER-109 versus placebo to prevent recurrent Clostridium difficile infection (RCDI) (ECOSPOR). https://clinicaltrials.gov/ct2/show/study/NCT0243 7487?term=seres\&rank=4. Accessed 2 Sep 2016.

222. SER-262 (SER-262-001 STUDY). http://www. serestherapeutics.com/ser-262-ser-262-001-study. Accessed 1 Oct 2016.

223. SER-262 versus placebo in adults with primary Clostridium difficile infection to prevent recurrence. https://clinicaltrials.gov/ct2/show/NCT02830542? term $=$ SER-262\&rank=1. Accessed 1 Oct 2016.

224. Petrof EO, Gloor GB, Vanner SJ, Weese SJ, Carter D, Daigneault $\mathrm{MC}$, et al. Stool substitute transplant therapy for the eradication of Clostridium difficile infection: "RePOOPulating" the gut. Microbiome. 2013;1:3. doi:10.1186/2049-2618-1-3.

225. MET-1 Clinical Pilot Study for Recurrent C. Difficile. https://clinicaltrials.gov/ct2/show/NCT02865616? term $=$ met-1\&rank=1. Accessed 2 Oct 2016.

226. Nagaro KJ, Phillips ST, Cheknis AK, Sambol SP, Zukowski WE, Johnson S, et al. Nontoxigenic Clostridium difficile protects hamsters against challenge with historic and epidemic strains of toxigenic BI/NAP1/027 C. difficile. Antimicrob Agents Chemother. 2013;57:5266-70. doi:10.1128/ AAC.00580-13.

227. Gerding DN, Meyer T, Lee C, Cohen SH, Murthy UK, Poirier A, et al. Administration of spores of nontoxigenic Clostridium difficile Strain M3 for prevention of recurrent $C$ difficile infection. JAMA. 2015;313:1719. doi:10.1001/jama.2015.3725.

228. Zhang K, Zhao S, Wang Y, Zhu X, Shen H, Chen Y, et al. The non-toxigenic Clostridium difficile CD37 protects mice against infection with a BI/NAP1/027 type of C. difficile strain. Anaerobe 2015;36:49-52. doi:10.1016/j.anaerobe.2015.09.009.

229. Winston JA, Theriot CM. Impact of microbial derived secondary bile acids on colonization resistance against Clostridium difficile in the gastrointestinal tract. Anaerobe. 2016;41:44-50. doi:10.1016/j.anaerobe.2016.05.003.

230. Theriot CM, Bowman AA, Young VB. Antibiotic-induced alterations of the gut microbiota alter secondary bile acid production and allow for Clostridium difficile spore germination and outgrowth in the large intestine. mSphere 2015;1:e00045-15. doi:10.1128/mSphere. 00045-15.Editor.

231. Weingarden AR, Chen C, Zhang N, Graiziger CT, Dosa PI, Steer CJ, et al. Ursodeoxycholic acid inhibits Clostridium difficile spore germination and vegetative growth, and prevents the recurrence of ileal pouchitis associated with the infection. J Clin Gastroenterol. 2016;50:624-30. doi:10.1097/MCG. 0000000000000427.

232. Howerton A, Ramirez N, Abel-Santos E. Mapping interactions between germinants and Clostridium difficile spores. J Bacteriol. 2011;193:274-82. doi:10. 1128/JB.00980-10.

233. Howerton A, Patra M, Abel-Santos E. A new strategy for the prevention of Clostridium difficile infection. J Infect Dis. 2013;207:1498-504. doi:10.1093/ infdis/jit068.

234. de Gunzburg J, Ducher A, Modess C, Wegner D, Oswald S, Dressman J, et al. Targeted adsorption of molecules in the colon with the novel adsorbent-based Medicinal Product, DAV132: a proof of concept study in healthy subjects. J Clin Pharmacol. 2015;55:10-6. doi:10.1002/jcph.359.

235. de Gunzburg J, Ghozlane A, Ducher A, Duval X, Ruppé E, Pulse $M$, et al. DAV132, an Adsorbent-Based Product, Protects the Gut Microbiome and Prevents Clostridium difficile Infections during Moxifloxacin Treatments. IDWeek, San Diego: 2015.

236. Miossec C, Sayah- Janne S, Augustin V, Chachaty E, Weiss W, Pulse $M$, et al. DAV131, an oral adsorbent-based product, fully protects hamsters against mociflocavin-induced Clostridium difficile lethal infection. Denver: Intersci Conf Antimicrob Agents Chemother; 2013.

237. Safety and Efficacy Study of Different DAV132 Dose Regimens in Healthy Volunteers. https:// clinicaltrials.gov/ct2/show/NCT02917200?term=da v132\&rank=2. Accessed 3 Oct 2016.

238. DAV132-Preventing occurence and recurrence of Clostridium difficile infection. http://www. davolterra.com/content/dav132-preventing-occure nce-and-recurrence-clostridium-difficile-infection. Accessed 3 Oct 2016.

239. Stiefel U, Nerandzic MM, Koski P, Donskey CJ. Orally administered beta-lactamase enzymes represent a novel strategy to prevent colonization by Clostridium difficile. J Antimicrob Chemother. 2008;62:1105-8. doi:10.1093/jac/dkn298.

240. Kokai-Kun JF, Bristol JA, Setser J, Schlosser M. Nonclinical safety assessment of SYN-004: an Oral $\beta$-lactamase for the protection of the gut microbiome from disruption by biliary-excreted, intravenously administered antibiotics. Int J Toxicol. 2016;35:309-16. doi:10.1177/1091581815623236.

241. Roberts T, Kokai-Kun JF, Coughlin O, Lopez BV, Whalen H, Bristol JA, et al. Tolerability and pharmacokinetics of SYN-004, an orally 
administered $\beta$-lactamase for the prevention of Clostridium difficile-associated disease and antibiotic-associated diarrhea, in two phase 1 studies. Clin Drug Investig. 2016;36:725-34. doi:10.1007/s40261-016-0420-0.

242. Stiefel U, Nerandzic MM, Pultz MJ, Donskeya CJ. Gastrointestinal colonization with a cephalosporinase-producing Bacteroides species preserves colonization resistance against vancomycin-resistant Enterococcus and Clostridium difficile in cephalosporin-treated mice. Antimicrob Agents Chemother. 2014;58:4535-42. doi:10.1128/ AAC.02782-14.

243. Carneiro BA, Fujii J, Brito GAC, Alcantara C, Oriá $\mathrm{RB}$, Lima AAM, et al. Caspase and bid involvement in Clostridium difficile toxin A-induced apoptosis and modulation of toxin A effects by glutamine and alanyl-glutamine in vivo and in vitro. Infect Immun. 2006;74:81-7. doi:10.1128/IAI.74.1.81-87. 2006.

244. Rodrigues RS, Oliveira RAC, Li Y, Zaja-Milatovic S, Costa LB, Braga Neto MB, et al. Intestinal epithelial restitution after TcdB challenge and recovery from Clostridium difficile infection in mice with alanyl-glutamine treatment. J Infect Dis. 2013;207:1505-15. doi:10.1093/infdis/jit041.
245. Efficacy study of alanyl-glutamine supplementation for the treatment of $C$. difficile infection. https:// clinicaltrials.gov/ct2/show/NCT02053350?term= alanyl-glutamine\&rank=2. Accessed 3 Oct 2016.

246. Li Y, Figler RA, Kolling G, Bracken TC, Rieger J, Stevenson RW, et al. Adenosine A2A receptor activation reduces recurrence and mortality from Clostridium difficile infection in mice following vancomycin treatment. BMC Infect Dis. 2012;12:342. doi:10.1186/1471-2334-12-342.

247. Cavalcante IC, Castro MV, Barreto ARF, Sullivan GW, Vale M, Almeida PRC, et al. Effect of novel A2A adenosine receptor agonist ATL 313 on Clostridium difficile toxin A-induced murine ileal enteritis. Infect Immun. 2006;74:2606-12. doi:10.1128/IAI. 74.5.2606-2612.2006.

248. Warren CA, Calabrese GM, Li Y, Pawlowski SW, Figler RA, Rieger J, et al. Effects of adenosine A2A receptor activation and alanyl-glutamine in Clostridium difficile toxin-induced ileitis in rabbits and cecitis in mice. BMC Infect Dis. 2012;12:13. doi:10.1186/1471-2334-12-13. 